\title{
Test-Re-test Reliability of Sahrmann Lower Abdominal Core Stability Test for DII Baseball Athletes
}

\author{
Kelsey Quinn Dekart \\ West Virginia University
}

Follow this and additional works at: https://researchrepository.wvu.edu/etd

\section{Recommended Citation}

Dekart, Kelsey Quinn, "Test-Re-test Reliability of Sahrmann Lower Abdominal Core Stability Test for DII Baseball Athletes" (2014). Graduate Theses, Dissertations, and Problem Reports. 125.

https://researchrepository.wvu.edu/etd/125

This Thesis is protected by copyright and/or related rights. It has been brought to you by the The Research Repository @ WVU with permission from the rights-holder(s). You are free to use this Thesis in any way that is permitted by the copyright and related rights legislation that applies to your use. For other uses you must obtain permission from the rights-holder(s) directly, unless additional rights are indicated by a Creative Commons license in the record and/ or on the work itself. This Thesis has been accepted for inclusion in WVU Graduate Theses, Dissertations, and Problem Reports collection by an authorized administrator of The Research Repository @ WVU. For more information, please contact researchrepository@mail.wvu.edu. 
Test-Re-test Reliability of Sahrmann Lower Abdominal Core Stability Test for DII Baseball Athletes

Kelsey Quinn Dekart, MS, ATC

\author{
Thesis submitted to the \\ College of Physical Activity and Sports Sciences \\ at West Virginia University \\ In partial fulfillment-of the requirements \\ For the degree of
}

\author{
Masters of Science \\ In \\ Athletic Training \\ Michelle A. Sandrey, PhD, ATC, Chair \\ Allison Hetrick, MS, ATC \\ Damien Clement, PhD, ATC, CC-AASP, NCC \\ Department of Sport Sciences
}

Morgantown, West Virginia

2014

Keywords: Core stability, Sahrmann model, Reliability, Lumbo-pelvic stability, Baseball

Copyright 2014 Kelsey Dekart 


\section{ABSTRACT}

Test-Re-test Reliability of Sahrmann Lower Abdominal Core Stability Test with Baseball Athletes

$$
\text { Kelsey Quinn Dekart, ATC }
$$

Context: Baseball athletes need to maintain a strong core for functional activities. The core not only transfers the energy from the hips to the throwing arm, but maintains stability and can decrease injury rates. There are several tests represented in the literature to measure core stability, but none have been advocated to use for baseball. Objective: The purpose of this study was to determine the reliability of the Sahrmann lower abdominal core stability in baseball. Design: The study was conducted as a prospective test re-test design. Setting: The testing took place at one location and only one clinician administered the testing. Data collection took place at the athletic facilities on the campus of a Division II Mid-Atlantic University. Patients and Other Participants: A totally of 30 participants from a D-II baseball program will be used for this study. The subjects were $19.73 \pm 1.41$ year's old, $83.93 \pm 6.94 \mathrm{~kg}$ in weight and $180.68 \pm 5.06 \mathrm{~cm}$ in height. All participants volunteered for the study and were current players encompassing a variety of positions, and were injury free within 6 months. Interventions: The participants were asked to complete as much of the Sahrmann lower abdominal core stability test correctly. There was no warm up prior to testing. The testing protocol was demonstrated and there was a training period consisting of 2 sub-max trials. The data was collected over a two week period. Main Outcomes Measures: The dependent variable was the result of the Sahrmann lower abdominal core stability test. Results: Overall, the ICC score for the Sahrmann lower abdominal test was ICC $3_{3,1=0.649}$ ( $95 \%$ confidence interval $=.257$ to $.832, \mathrm{P}=.003$ ). This ICC value reflects moderate reliability for the Sahrmann lower abdominal test. The standard error of the measurement (SEM) value that is reported is SEM $=0.302$, which would be described as low. Conclusions: Until further studies are conducted it is difficult to determine whether Sahrmann lower abdominal core test is a valid core stability test because there is no core stability gold standard. Determining a gold standard to measure core specifically may be difficult. There are multiple concepts and philosophies about core, stability, strength, endurance, and power. The Sahrmann core stability test has moderate reliability when used with Division II baseball athletes at one institution. 


\section{ACKNOWLEDGEMENTS}

I would like to start by thanking my family. I am truly blessed to have such great people to support me. Being away from home these past two years has been hard, but your words of encouragement were never unheard. I appreciate you and thank you very much for all you do.

I would also like to thank Tommy Cathell, you have been my rock through all of my trials. I'm blessed for your loving support.

I would also like to thank my graduate advisor, Dr. Michelle Sandrey. I know you spent countless hours editing and working with me on this project. I appreciate all your time.

Thanks to my committee members, Dr. Damien Clement, and Allison Hetrick. I am grateful for your time and effort you have placed into this process.

I would also like to thank Bob Cable. I have enjoyed working side by side with you and your knowledge has helped to create me as an athletic trainer.

I would like to extend a special thank you to Coach George Yanchak, the Fairmont State Baseball coaching staff and the Team. Thank you for volunteering as participants and truly making me part of the team. Best Wishes to you in the future. 


\section{TABLE OF CONTENTS}

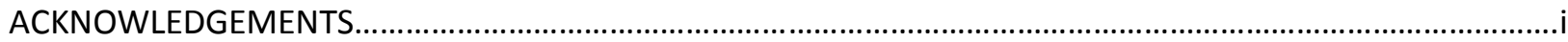

LIST OF TABLES

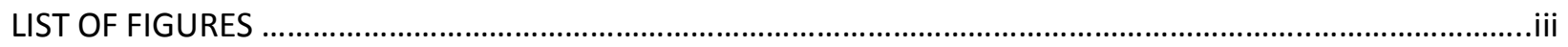

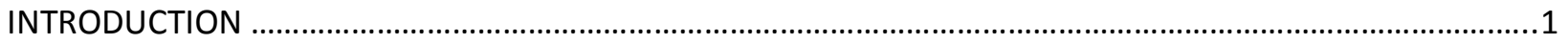

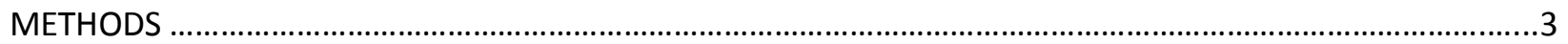

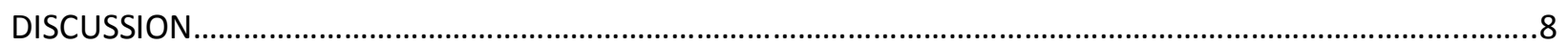

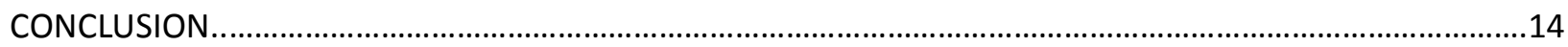

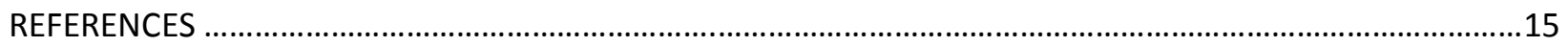

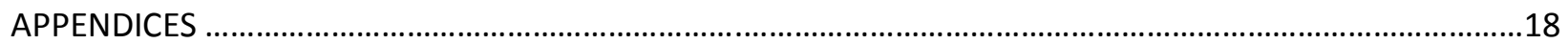

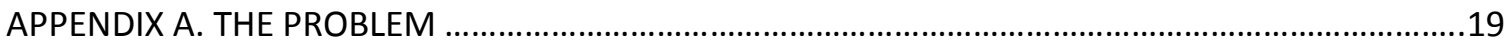

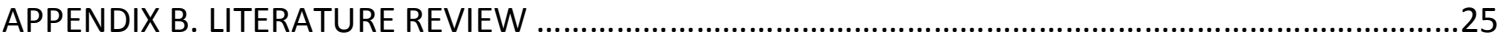

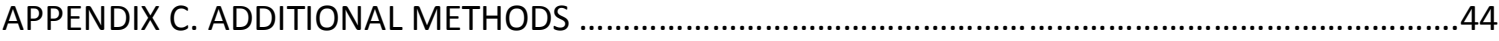

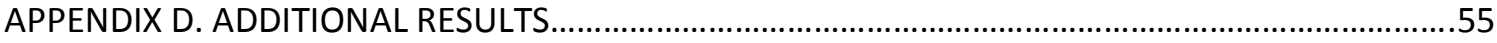

APPENDIX E. RECOMMENDATION FOR FUTURE RESEARCH..................................................56

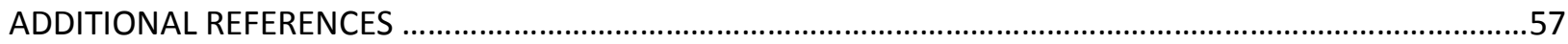




\section{LIST OF TABLES}

Table

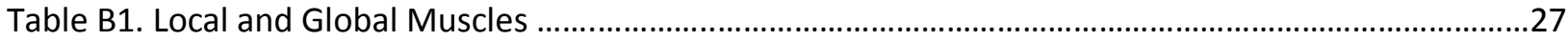

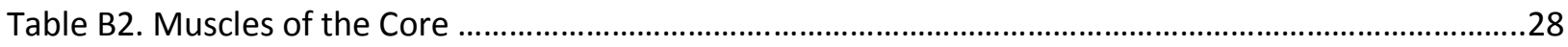

Table B3. Measurement of Core Stability Literature Review ..................................................................39

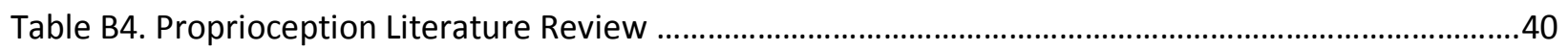

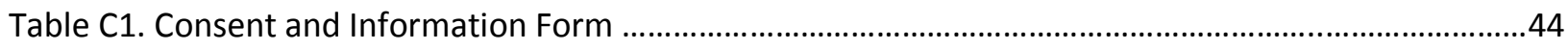

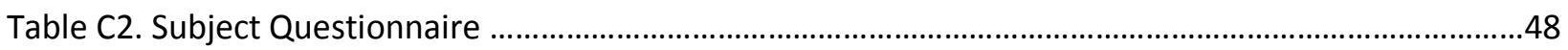

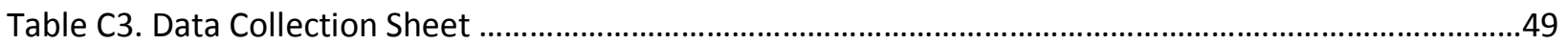

Table D1. ICC Scores, Standard Error of the Measurement and Means and Standard Deviation Between

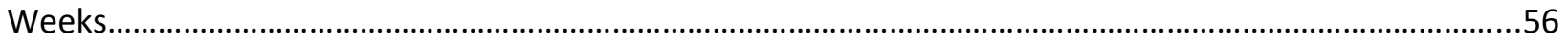




\section{LIST OF FIGURES}

Figure $\quad$ Page

Figure C1. Sahrmann Lower Abdominal Level 1...................................................................................50

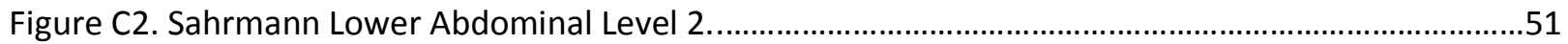

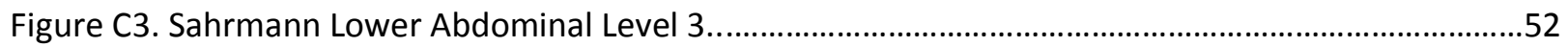

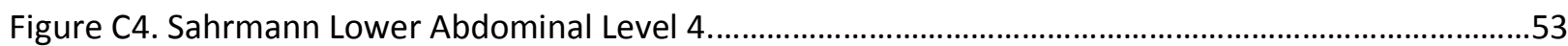

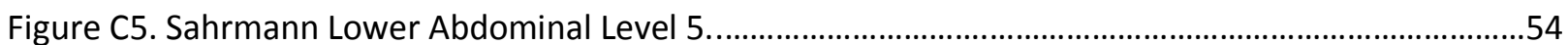




\section{INTRODUCTION}

Core stability has often been referred to as core strength or core endurance. ${ }^{1,2}$ Of the three terms, core stability has been deemed the most important and is referred to as "the ability of passive and active stabilizers in the lumbo-pelvic region to maintain appropriate trunk and hip posture, balance and control during both static and dynamic movements". ${ }^{2}$ Both the global and local muscles ${ }^{3,4,5,6,7,8}$ and non-contractile tissue ${ }^{9,10,11}$ control the position and contribute to the serape effect. The core is the connector from the lower to the upper body, and is thought to initiate movement and provide a stable base for the extremities ${ }^{12,13,5}$ as well as a transfer of energy for many sports, including baseball. ${ }^{14}$

Core stability has been evaluated with many different tests on the clinical and research side as there is no gold standard ${ }^{9}$ for the assessment of core stability. McGills endurance testing, quadruped arm raise test, front and side abdominal power test have been reported in the literature. ${ }^{15}$ Other sources $4,16,17,18,19$ evaluated a link with training the core and performance. McGill ${ }^{15}$ compared the endurance test to functional tests such as 1RM (repetition max) bench, ${ }^{20}$ or squat, ${ }^{20}$ Functional Movement Screen (FMS), ${ }^{21} 10$ yard shuttle run, ${ }^{20}$ among others. The quadruped arm raise test used in Liemohn's study was evaluated with a stability platform and was scored by the time each participant maintained balance. ${ }^{22}$ They found that this test should be considered a sound test to evaluate core stability. ${ }^{22}$ Using a test-retest reliability design, ICC values reported favored the front and side abdominal power tests. ${ }^{23}$ The two power tests and the quadruped arm raise tests are a few evaluation tools that have been evaluated for reliability and have the ability to be performed easily in the field.

It has been suggested that the Sahrmann lower abdominal test be used by contemporary physical therapists trying to systematically and comprehensively evaluate and treat their patients. ${ }^{24}$ Sahrmann lower abdominal core stability test is thought to recruit the "core stabilizers" specifically, ${ }^{25}$ and reflects the notion that local abdominal muscles, especially the transverse abdominus, provide control with spinal loading and support the spine. ${ }^{25}$ The Sahrmann lower abdominal test is comprised of 
5 different levels of increasing difficultly for core stability evaluation. The basic breath is the starting position for all of the levels to come. All positions start supine in the hook lying position, with the spine in a neutral or comfortable position. Each level consists of a series of leg movements while maintaining abdominal stability. These movements can be flexion and extension of the knee, or lowering a straight leg down to the table. The testing has been used to train, strengthen, and test individual's core stability and lower abdominal strength (C. Endicott, written communication 2013). Each test challenges the athlete's core stability and determines at what level core stability will fail or not be strong enough to continue.

It is not known if baseball players need core endurance, strength or stability. Due to the throwing and hitting mechanics, baseball is believed to have a strong correlation between the need for stability and power. The core acts as a link between the force exchange and maintaining stability during the early cocking phase of a pitch or throw along with contact of the ball during batting. This link helps direct the power from the legs and hips up the kinetic chain into the throwing arm and eventually the baseball. As everything needs to work from a stable base, this allows the athlete to stand on one leg in a stable position. Functionally during a throwing motion with baseball athletes, especially pitchers but also field players, there is a point when an unstable falling position or single leg position is evident. This is when the importance of core falls into play. Baseball players need the ability to maintain a stable position when on a single leg or off balance but also need a good transfer of energy from the lower body through the core and scapula down the shoulder and arm for a strong throw. ${ }^{26}$ There will be times when a catcher may hop up, off balance, or an outfielder will throw a ball from a lying position on the ground, these are examples of possible unstable positions baseball athletes may be placed into. When there is poor functioning of local muscles, especially TrA's and multifidus, it is often associated with dysfunctional movement patters. ${ }^{25}$ In each situation, core stability supplies the body with improved function of the lower extremities. ${ }^{25}$ During each situation the athletes will be in a more stable position if 
they have a correctly functioning core. It is also apparent, but is little research on, when batting, the transfer of energy is important and related directly to the serape effect. It has been recognized that to maintain the high muscle activity in the trunk muscles, there needs to be considerable low back and abdominal stabilization with core training focusing on resisted trunk rotations while improving thoracic and hip mobility. ${ }^{27}$

There is an importance for a strong core in baseball athletes but there is also a lack of standardized definition, protocol and reliability research conducted incorporating core stability. Along with limited identifiable tests there is very little research on the specifics of core that relate to individual sports, such as baseball. Therefore, a measurement technique that is applicable for the clinical athletic trainer is paramount, especially for baseball athletes. Anecdotal evidence supports the use of Sahrmann lower abdominal core stability testing (C. Endicott, written communication 2013. However, there is very little research on the Sahrmann core stability test. As of now, there are no known test-retest reliability studies that have used Sahrmann lower abdominal testing to evaluate core stability using all five levels. ${ }^{17}$ Furthermore, there is limited information in the literature in regard to baseball players and core stability evaluation. Thus, since core stability is important in baseball players, a study is needed to evaluate core stability using baseball players. Further, as test-re-test reliability is not evident for Sahrmann lower abdominal testing, nor about the use with baseball players, the purpose of this study is to determine the test re-test reliability of the Sahrmann Lower Abdominal test using baseball players. METHODS

This study was conducted as a prospective tests re-test design to establish reliability. The Sahrmann Lower Abdominal test was measured using the 5 levels. The Sahrmann test was demonstrated for each subject prior to completion of the testing period. Actual data was collected at the same site for the next two testing periods. Data was collected over a period of two weeks with a total of two testing periods completed. 


\section{SUBJECTS}

A total of 30 subjects have completed the three testing periods. A sample of convenience was used. The subjects were from a D-II baseball program in a Mid-Atlantic State and were asked to volunteer for this study. Subjects were between $18-22$ years old $(19.73 \pm 1.41)$, with a mass of $83.93 \pm$ $6.94 \mathrm{~kg}$ and height of $180.68 \pm 5.06 \mathrm{~cm}$. The subjects were divided into groups based on position, pitcher, in-field, or out-field. The participants had no lower body injuries that would affect performing the Sahrmann stability test and were free of lower extremity injury within the last six months. Each subject was listed on the active roster for the team. Exclusion criteria consisted of the subjects not undergoing any balance or core stability training during the testing period. Prior to the initiation of the study, the study was approved by the Office of Research Compliance at West Virginia University and Fairmont State University.

\section{INSTRUMENTS}

The Sahrmann lower abdominal test is comprised of 5 different levels of increasing difficultly for core stability evaluation. The basic breath is the starting position for all of the levels to come. All positions start supine in the hook lying position, and the spine should be in a neutral or comfortable position. Each level consists of a series of leg movements while maintaining abdominal stability. These movements can be flexing and straightening the knee, or lowering a straight leg down to the table. The testing has been used to train, strengthen, and test individual's core stability and lower abdominal strength (C. Endicott, written communication 2013). Each test challenges the athlete's core stability and determined at what level core stability will fail or not be strong enough to continue. One study reported had pilot data with a reliability coefficient of 0.95 with a TEM of $7.7 \%$ for the Sahrmann core stability test. ${ }^{17}$ Very little research has used the Sahrmann core stability test. Thus, the ICCs of the Sahrmann core stability test have not been determined. 


\section{TEST PROTOCOL}

Week 1: The subjects participated in a training session. The training session allowed two sub max trails of each test. Week 2 and 3: These two weeks was the testing sessions for the Sahrmann lower abdominal test. The subjects began at level one and progressed only if the previous level was passed. This test was done at each testing session by the same clinician.

\section{PROCEDURES}

Prior to the testing period a meeting was held with the entire baseball team to go over the informed consent with HIPPA form (Table C1), and the inclusion criteria questionnaire (Table C2). After signing the forms and reviewing the inclusion criteria only the baseball players that met the criteria set by the experimenter were included. For the Sahrmann lower abdominal test the pressure was started once the athlete was in the proper position (Figure $\mathrm{C} 1,2,3,4,5)$. The athlete was to progress through one repetition of the level while maintaining $60 \mathrm{mmHG}$ in the blood pressure cuff allowing a $10 \mathrm{mmHG}$ fluctuation either way (plus or minus). The pressure of $60 \mathrm{mmHG}$ was adjusted when the athlete was in the $90 / 90$ position with hips flexed to $90^{\circ}$ and the knees flexed to $90^{\circ}$. There was a minute rest period before beginning the successive level. Before testing each level the athlete was allowed 3 sub maximal attempts while looking at the pressure gauge. During testing the athlete was not allowed to view the gauge, and the investigator determined pass or fail according to the gauge. The athlete was allowed two maximal tests. The Sahrmann test was progressed only if the athlete was able to maintain between $50 \mathrm{~mm} \mathrm{HG}$ and $70 \mathrm{mmHG}$ on the previous level.

Sahrmann lower abdominal test: The Sahrmann lower abdominal test is comprised of 5 different levels of increasing difficultly for core stability evaluation. The basic breath is the starting position for all of the levels to come. All positions start supine in the hook lying position, with the spine in a neutral or comfortable position. The first movement was with one leg moving into $90^{\circ}$ hip flexion. (Figure C1) Maintaining abdominal control, the opposite leg was then matched to the first by moving into $90^{\circ}$ of hip 
flexion. One leg at a time was lowered to the table again, maintaining abdominal control by staying in spine neutral. Level 2 (Figure C2) again began at the same position as one leg was raised into $90^{\circ}$ hip flexion, matching the position with the opposite leg. One leg was lowered to a heel touch position on the table and extended out along the table, then returned to the starting position. This was also done with the opposite leg. Level 3 (Figure C3) started with both legs brought up into $90^{\circ}$ hip flexion. One leg at a time was extended out and did not contact the table but remained 1-2 inches above the table. The opposite leg again mimicked the first and the patient returned back to the hook lying position on the table. Level 4 (Figure C4) was started with the athlete fully extended lying on the table. Heels were in contact with the table and the knees were flexed to a fully flexed position and extended back down to the table. This was done while spine neutral was maintained. Level 5 (Figure C5) is the most difficult level that few people are able to obtain. It began again with legs extended lying on the table. Both legs were lifted off the table then the knees were flexed and brought up into hip flexion. The athlete then extended the knees out and lowered both legs down towards the table. All levels were completed while maintaining lumbar stabilization and spine neutral. ${ }^{28}$

\section{DATA ANALYSIS}

The ICC is a reliability coefficient that generates a ratio ranging from 0.00 to 1.00 to estimate the consistency of performance on repeated trials. ${ }^{29} \mathrm{~A}$ score of 0.00 indicates the measure was $100 \%$ unreliable. In calculating the ICC, the ratio determines accurate interpretation of how much variability in the observed measure was truly a change in the participant or if it is a result of measurement error. Therefore, an ICC over 0.75 can be considered good while anything below 0.5 is poor. ${ }^{30}$ Another common scale used for reliability as described by Portney and Watkins ${ }^{30}$ is that ICC $>.75$ is good and anything less than .75 reflects moderate to poor reliability. Furthermore, Anastasi ${ }^{31}$ suggests that an ICC of .60 is the minimal acceptable score for reliability. 


\section{STATISTICAL ANALYSIS}

ICCs or intraclass correlation coefficients was used to determine test re-test reliability of the Sahrmann lower abdominal test by analyzing the maximal effort measurements between trial 1 (week 2) and trial 2 (week 3). The following equation was used for the calculation of ICC as established by Shrout and Fleiss ${ }^{32}$ where BMS = between subjects mean square, EMS = between testing sessions mean square, $\mathrm{TMS}=$ trial mean square, $\mathrm{N}=$ number of total subjects, and $\mathrm{K}=$ number of testing sessions. $\mathrm{ICC} 3,1=$ $[\mathrm{BMS}-\mathrm{EMS}] /[\mathrm{BMS}+(\mathrm{K}-1) \mathrm{EMS}+(\mathrm{K}(\mathrm{TMS}-\mathrm{EMS}) / \mathrm{N})]$. The SEM or standard error of measurement was used to determine the precision of the recorded measurements. The SEM demonstrated the variation in expected scores for one subject if the test were repeated multiple times. The following equation was used for SEM as described by Brown ${ }^{33}$ where $S=$ the standard deviation of the test and rxx = reliability coefficient for the test.

$$
\mathrm{SEM}=\mathrm{S} \sqrt{1-\mathrm{rXx}}
$$

Furthermore, descriptive statistics was analyzed for all five components of the Sahrmann lower abdominal test. Specific measures will include means, standard deviations, and standard error of the measurement.

\section{RESULTS}

The means and standard deviation for week two and three along with the $\mathrm{ICC}_{3,1}$ can be found in Table D1. Overall, the ICC score for the Sahrmann lower abdominal test was ICC $3_{3,1}=0.649$ ( $95 \%$ confidence interval $=.257$ to $.832, P=.003$ ). This ICC value reflects moderate reliability for the Sahrmann lower abdominal test. The standard error of the measurement (SEM) value that is reported is $\mathrm{SEM}=0.302$, which would be described as low. This can be interpreted that any individual that has not participated in any core stabilization program would begin at a level 1 on that Sahrmann lower abdominal test and not deviate more than .3 from the highest level reached at any given time. 


\section{DISCUSSION}

The purpose of this study was to establish test re-test reliability for the Sahrmann lower abdominal core test. Although the Sahrmann lower abdominal core test is used clinically every day, there is little to no research conducted to determine the test re-test reliability of the Sahrmann lower abdominal core test for any sport. By including Division II baseball athletes, the results became relevant for a group where core stability evaluation could be of benefit. Reliability was moderate (0.649) with a low SEM reported. This low SEM can be interpreted that a clinician using the Sahrmann lower abdominal core test to evaluate a baseball athlete's core at one institution would stay fairly consistent over the 2 weeks of measure. It was hypothesized that the Sahrmann lower abdominal test was reliable and the test have high ICC values and be similar between weeks. This hypothesis was rejected due to the notion that 0.75 is high reliability. The ICC values were still notable to be moderate and similar between weeks.

Use Of Sahrmann Core Testing as a Screening Tool

It is important to note that in this study, moderate reliability but measurement consistency was noted for the protocol used from Colorado College. This protocol was followed as it best represented the intent of the original developer to clinically determine core activation ability, ${ }^{25}$ or challenge the athlete's core stability and determine at what level core stability will fail or not be strong enough to continue. Further, this protocol as described by Sahrmann is commonly used in the clinical evaluation of patients with low back pain. ${ }^{24,34}$ However, throughout the literature and while viewing general search engines (Google) and YouTube, the five levels of the Sahrmann lower abdominal core test were depicted with varying protocols. This may pose a problem when further research is conducted. Research has been linked to low back pain related to an inhibited or inactive core. ${ }^{1,16}$ As the Sahrmann lower abdominal core test is used to evaluate for core activation ability, ${ }^{25}$ it may be beneficial to look further into the Sahrmann protocol testing to solidify the protocol that should be used and the purpose for the 
measurement. As Sahrmann lower abdominal core test technique could be used to determine a weakened core for off season training, or possibly to determine injury prone athletes, further research is warranted.

As this is the first study to evaluate the test re-test reliability for the Sahrmann lower abdominal core test, there is very little research if any to use as a basis of comparison. Previous authors have found this a valid and reliable clinical measure of the capacity to isometrically recruit lower abdominal muscles involved in core stabilization. ${ }^{17,35,36}$ Anecdotal evidence supports the use of Sahrmann lower abdominal core stability testing (C. Endicott, written communication 2013. However, there is very little research on the Sahrmann core stability test. Only one other research study did follow the original Sahrmann protocol to evaluate for core activation ability, but used the results to divide participants in the study into a low (test score of 0 ) or high scoring group (test score of 1 or 2 ) to note the connection of the core with hip and knee kinematics. ${ }^{25} \mathrm{As}$ of now, there is no known test-retest reliability studies that have used Sahrmann lower abdominal testing to evaluate core stability using all five levels as depicted by Sahrmann. ${ }^{17}$

There is an importance for core but there is also a lack of a standardized definition, protocol and reliability and validity measures incorporating core stability in what has been reported in the literature. Most often McGills ${ }^{15}$ endurance test is evident in research with comparisons to functional and performance evaluations. Reliability studies for McGills ${ }^{15}$ endurance test have been conducted with a reliability coefficient of $>0.97$ for the repeated tests. ${ }^{15}$ However, some may argue the validity of any core stability test including McGills ${ }^{15}$ endurance test. Due to the vast definitions of core and function, core stability has yet to be validated; this is not exception with McGills testing. Some believe that McGills endurance testing is more specific to global muscles, not actually testing the deep local muscles that are so important for spinal stability. It may be possible to use a stability platform or a force plate to evaluate an individual's stability during the McGills ${ }^{15}$ endurance test, Sahrmann lower abdominal core 
test or a quadruped position. A force plate was used by Danis ${ }^{37}$ to determine proprioception stability with eyes opened and closed during double leg stance, which could also be used to establish reliability testing for the core. The quadruped position may also be used as a screening tool, ${ }^{39}$ as this has been shown to activate many local muscles but there is also activation of global muscles. Because of this, there is a connection of the core to the hip, hence the lumbo-pelvic hip complex concept. ${ }^{39}$ Leimohn ${ }^{22}$ also used the quadruped arm raise but research was conducted using a stability platform to test reliability. The reliability on each day was: day $1 ; r=0.97$, day $2 ; r=0.89$, day $3 ; r=0.95$, and day $4 ; r=0.92$. There is a need to establish a standardized protocol incorporating the quadruped position, Sahrmann lower abdominal core test or McGills endurance test that can be used in both the clinical setting and for further research studies. As core training has been represented in the literature and proposed to be used to enhance the athlete's function and performance, ${ }^{4,16,17,18,19}$ there needs to be a validated and reliable technique used to indicate whether a true core improvement is evident or if there are deficits still present. As there has been no determined gold standard for testing core stability, this would make testing validity difficult.

Core Stability Relationship to Baseball

Although there was only one specific research study evident that was conducted to determine core stability with baseball athletes, ${ }^{26}$ it is believed that baseball athletes have a need for core stability. First and foremost pitchers have a necessity for core stability due to the position they are in and the need for a transfer of energy. ${ }^{14}$ Pitchers habitually are placed in a single leg stance but are also required to transfer energy from legs through the core to the tips of fingers. Other positions in baseball are also in need of core stability as well. The simplest way to describe the other positions relationship to core is hitting. During hitting, the position is like a pitch without a single leg stance. The athletes are required to transfer the energy created from the legs and a twisting motion of the bat to hitting the ball forcefully. Hitting coaches and managers believe that the velocity of the bat is generated from the 
sequential rotational movement of the body during the swing. ${ }^{27}$ This is obviously just one way these athletes need a stable core. The idea of a kinetic link states that "one body segment will transfer forces to the next adjacent body segment when the action/motion is executed optimally", ${ }^{27}$ this could also be related to the serape effect and why the kinetic chain as a whole is important. Infield and out- fielders often times have demands of the game that will place them in an off balance position during a throw. To help with this correction biomechanically, the core is initiated to help stabilize. Kibler ${ }^{5}$ noted that $50 \%$ of the throwing motions force and energy comes from the hip and trunk area. When baseball athletes recruit the core musculature it is important to remember the Serape effect ${ }^{14}$ and that rotational exercises must be incorporated to strengthen in many planes. ${ }^{12}$ Often times there are imbalances that are present; they are seen especially with baseball athletes, such as tight hips flexors, and rounded forward shoulders. ${ }^{40}$ All of these imbalances lead to abnormal spinal loading creating an unsafe environment for the body and risk of injury. ${ }^{40}$ Although there is great evidence linking the core to many if not all sports, there are still questions to how strength coaches, AT's and PT's should train and rehabilitate their athletes when pertaining to the core. ${ }^{41}$

When many look at a pitching motion most of the focus is spent evaluating the shoulder and elbow activity to help increase efficiency of a pitch. ${ }^{26}$ After much thought the hip and torso also play a limitless role in the pitching motion. ${ }^{26}$ There has been studies that show pitchers with larger ground reaction force throw the fastest. ${ }^{26}$ This would have to suggest that these forces are accurately being transferred through the torso or "core" region and into the shoulder and elbow. ${ }^{26}$ Proper lumbo-pelvic control is a key to having a powerful, high velocity and accurate pitch. ${ }^{26}$

There are many professionals interested in the relationship core has to each sport. ${ }^{16}$ Strength coaches, Athletic Trainers, and Physical Therapist all want to understand the relationship core has to performance, injury prevention or rehabilitation. When looking at the relationship of a 1 RM bench press, $1 \mathrm{RM}$ squat, countermovement vertical jump, 40 yard spring and 10 yard shuffle, there were no 
significant correlations identified. ${ }^{20}$ This and many other research shows that there is controversial thoughts as to what types of core is needed and how to train or rehabilitate it.

In this study, most of the athletes only progressed to level 1 and some were not able to pass

level 1. This was also similar to the population in the Shirey et al. ${ }^{25}$ study in which subjects scoring ranged from 0 to 1 . Perhaps this is the norm for most individuals, as in that study, 0 was determined as low and 1-2 was considered high. In this study, there could be multiple reasons for this occurrence. One would hope it was due to the test being difficult and sensitive to the actual core stability level present in that baseball athlete. However, it is possible the athletes lacked the effort to continue the test, or misunderstood what they were asked to do, or did not understand the relationship of the blood pressure cuff to performing the Sahrmann lower abdominal core stability test. Using baseball as a sample of convenience was also intentional due to the relationship between core and the functional movements in baseball. The hope was that these specific athletes would demonstrate satisfactory core stability as pertaining to the Sahrmann lower abdominal core stability testing. This however, was not illustrated by the results. Despite all athletes scoring a 1, one athlete progressed to level 4 for week two, but was only able to progress to level 1 the following testing period. This would be considered an outlier for this data, conversely a level zero, was more of a norm so that value would not be considered an outlier. Since this information is not generalizeable to other baseball athletes, it can only be hypothesized that other athletes (football, basketball, soccer) would also show similar results and reliability. Due to the need for baseball athletes to maintain core stability during functional tasks, it is thought that football athletes may present with lower scores than this baseball team. With the idea there is a larger variance of size and athletic ability it is possible core stability is not represented within training programs as well for a football population. 


\section{Clinical Relevance}

Controversy leads to new thoughts or understanding of other predetermined thoughts. Because this study is the first of its kind this poses importance clinically. The motivating factor behind the idea of this study was to create an assessment tool in order to determine the need for a core stability program in the off season. This kind of assessment would allow Athletic Trainers to asses' core stability and determine the need of a strengthening/training program over the summer months for prevention. When using the Sahrmann lower abdominal core test all that is needed is a blood pressure cuff that most, if not all athletic training rooms or facilities should have. This allows for multiple facilities and professionals to use this technique easily. Although this research can only be generalizable to one Division II baseball team, there are implications for the Sahrmann core test to be used clinically as has been reported in the literature. ${ }^{17,25,35,36}$ Core stability has been advocated for sports activities to find weaknesses and imbalance, but this is not the only piece to the puzzle of keeping the athletes healthy and performing at the highest level. Core is the ability to maintain postural positioning and transfer energy. These are both needed for athletes to continue functioning optimally. Baseball athletes are required to maintain a stable position on a single leg but also to transfer energy from the lower body through the core and scapula down to the shoulder and arm for a strong throw ${ }^{26}$ thus, the need for a reliable and valid core stability test is paramount. The Sahrmann lower abdominal core test showed low SEM values to prove that it was accurately measuring the level each athlete was at, but without validity the advocacy of this test can be suspect. Further studies are warranted to verify the use of this core test in the clinical setting Limitations of the Study

There were a few limitations of the study. Within these limitations were uncontrollable variables. There was a testing period in which the location had a power outage, but it was possible to test in a different location. This one testing day was in the Athletic Training Room on treatment tables 
while the rest of the days the participants tested on the hard auxiliary floor. Also there were a few participants that complained of fatigue from lifting days earlier. There was a group, specifically the pitchers that were placed on a "core stability" program. However, it was determined that the program that the pitchers were using did not specifically train the local core stabilizers. It was programmed specifically for global muscles of the core. In the instance this program was directly related to core stability, it would have been noted that those pitchers would have had an obvious difference in the levels attained. Therefore, this program had a possibility to be a limitation, but because it had no effect on the pitchers Sahrmann scores, it appears to not be a limitation.

\section{CONCLUSIONS}

Until further studies are conducted it is difficult to determine whether Sahrmann lower abdominal core test is a valid core stability test because there is a lack of a core stability gold standard. Determining a gold standard to measure core specifically may be difficult, but there is an option. There are multiple concepts and philosophies about core, stability, strength, endurance, and power. Nevertheless, the Sahrmann core stability test has moderate reliability when used with Division II baseball athletes at one institution. In order to better determine the reliability and core stability and advocate clinical use, it may be necessary to test athletes when they are not in season or doing any workouts. This should be a consideration when further studies are conducted to evaluate the reliability of the Sahrmann test with other groups. 


\section{REFERENCES}

1. Urquhart DM, Hodges Pw, Allen TJ, Story IH. Abdominal muscle recruitment during a range of voluntary exercises. Man Ther. 2004; 10:144-153.

2. Reed CA, Ford KR, Myer GD, Hewett TE. The Effects of isolated and intergrated core stability training on athletic performance measures. Sport Med. 2012; 42 (8):697-706.

3. Wier A, Darby J, Inklaar H, Koes B, Bakker E, Tol J. Core stability: Inter- and intraobserver reliability of 6 clinical tests. Clin J Sport Med. 2010; 20(1):34-38.

4. Okada T, Huxel KC, Nesser TW. Relationship between core stability, functional movement, and performance. Strength Cond. 2011; 24(1):252-261.

5. Kibler WB, Press J, Scascia A. The role of core stability in athletic function. Sports Med. 2006; 36(3):189-198.

6. Leetun DT, Ireland ML, Willson JD, Ballantyne BT, Davis IM. Core stability measures as risk factors for lower extremity injury in athletes. Medicine \& science in Sports \& Exercises. 2004; 36(6):926-934.

7. Peate WF, Bates G, Lunda K, Francis S, Bellamy K. Core strength: a new model for injury prediction and prevention. J Occu Med Toxi. 2007; 2(3):1-9.

8. Biely S, Smith S, Silfies S. Clinical instability of the lumbar spine: Diagnosis and intervention. Orthopaedic Practice. 2006:18(3); 11-18

9. Hibbs A, Thompson K, French D, Wrigley A, Spears I. Optimizing performance by improving core stability and core strength. Sports Med. 2008:35(12); 995-1108.

10. Hodges P. Core stability exercise in chronic low back pain. Orthop Clin N Am. 2003:34; 245-254.

11. Lederman E. The myth of core stability. J Bodywork Movement Therapies. 2010:14; 84-98.

12. Cissik, J. Programming abdominal training, Part II. Strength Cond. 2002:24(2); 9-12.

13. Fredericson M, Moore T. Muscular balance, core stability, and injury prevention for middle and long distance runners. Physical medicine and rehabilitation clinics of North America. 2005; 16:669-689.

14. Logan GA, McKinney WC. Anatomic Kinesiology. 3 Sub Edition: 1982.

15. McGill S, Childes A, Liebenson C. Endurance times for low back stabilization exercises: Clinical targets for testing and training from a normal database. Journal of Arch Phys Med Rehabil. 1999:80; 941-944.

16. Nesser TW, Huxel KC, Tincher JL, Okada T. The relationship between core stability and performance in division I football players. Strength Cond. 2008; 22(6):1750-1754 
17. Stanton $\mathrm{R}$, Reaburn $\mathrm{P}$, Humphries $\mathrm{B}$. The effect of short term swiss ball training on core stability and running economy. Strength Cond. 2004: 18(3); 522-528.

18. Saeterbakken A,Tillaar R, Seiler S. Effect of core stability training on throwing velocity in female handball players. Strength Cond. 2011:25(3); 712-718.

19. Lust K, Sandrey M, Bulger S, Wilder N. The effects of a 6-week training programs on throwing accuracy, proprioception, and core endurance in baseball. J Sport Rehabil. 2009:18; 407-426.

20. Nesser $\mathrm{T}$, Lee $\mathrm{W}$. The relationship between core strength and performance in division I female soccer players. Exerc Physiologyonline. 2009:2(12); 21-28.

21. Basnett C, Hanish M, Wheeler T, Miriovsky D, Danielson E, Barr J, Grindstaff T. Ankle dorsiflexion range of motion influcences dynamic balance in individuals with chronic ankle instability. Sports Phys Ther. 2013; 8(2):121-128

22. Liemohn W, Baumgartner T, Fordham S, Sirvatsan A. Quantifying core stability: A technical report. Strength Cond. 2010:24(2); 575-579.

23. Cowley P, Swensen T. Development and reliability of two core stability field tests. Strength Cond. 2008:22(2); 619-624.

24. Hoover D. The concurrent validity of abdominal strength measures using the sahrmann model and an isointertial device. Thesis and Dissertation. 1994.

25. Shirey M, Hurlbutt M, Johansen N, King GW, Wilkinson SG, Hoover DL. The influence of core musculature engagement on hip and knee kinematics in women during a single leg squat. Int $J$ Sports Phys Ther. 2012;7(1):1-12.

26. Chaudhari A, McKenzie C, Borchers J, Best T. Lumbopelvic control and pitching performance of professional baseball pitchers. Strength Cond. 2011:25(8); 2127-2132.

27. Szymanski DJ, DeRenne C. The Effects of Small Muscle Training on Baseball Hitting Performance: A Brief Review. Strength Cond. 2010;32(6):99-108.

28. Sahrmann 5 [DVD] Colorado College (Denver, CO) where Human Kinetics is, year 2004

29. Drouin JM. How should we determine a measurement is appropriate for clinical practice? Athl Ther Today. 2003; 8(4):56-58.

30. Portney LG, Watkins MP. Foundations of Clinical Research: Applications to Practice. EastNorwalk, Conn: Appleton \& Lange; 1992.

31. Anastasi A. Psychological Testing. 6th ed. New York, NY: Macmillan; 1998. 
32. Shrout PE, Fleiss JL. Intraclass correlations: uses in assessing rater reliability. Psychol Bull. 1979; 86:420-428.

33. Brown, JD. Standard error vs standard error of measurement. JALT Testing \& Evaluation SIG Newsletter. 1999; 3(1):20-25.

34. Faries MD, Greenwood M. Core training: stabilizing the confusion. Strength Condit J. 2007;29(2):10.

35. Hoover DL, Zebas CJ, Frye BB, Loudon JK, Liu W. The concurrent validity of abdominal strength measures using the Sahrmann model and a B-200 isoinertial device. Phys Ther. 2005;85(5).

36. Hoover D, Cinotto J, Harshman H, Stansberry D, Woodworth S. The concurrent validity of goniometry and 3-D motion analysis for assessing pelvic motion during the "bent knee fallout" test. J Ortho Sports Phys Ther. 2010;40(1):A77-78.

37. Danis C, Krebs D, Gill-Body K, Sahrmann S. Relationship between standing posture and Stability. Phys Ther. 1998:78(5); 502-517.

38. Willardson J. Core stability training for healthy athletes: A different paradigm for fitness professionals. Strength Cond. 2007:29(6); 42-49.

39. Stevens V, Vleeming A, Bouche K, Mahieu N, Vanderstraeten G, Danneels L. Electromyographic activity of trunk and hip muscles during stabilization exercises in four-point kneeling in healthy volunteers. Eur Spine J. 2007:16; 711-718.

40. De Riddler E, Van Oosterwijck J, Vleeming A, Vanderstraeten G, Danneels L. Posterior muscle chain activity during various extension exercises: An observational study.BMC Musculoskeletal Disorders. 2013:14

41. Oritz A, Olson S, Libby C. Core stability for the female athlete: A review. Women's Health Phys Ther. 2006:30(2); 11-17. 
APPENDICES 


\section{APPENDIX A}

\section{THE PROBLEM}

There are many different terms for core stability. Often times pelvic neutral, spine neutral or core strength are used. Most often "core" is thought of as the abdominal muscles, but there are other aspects of core; such as strength, endurance, and stability. Core strength is often evaluated, but is not as important as endurance or stability. Core strength is defined as the ability of the core to generate and maintain force. ${ }^{2}$ However, the term core stability is most important, and is known as "the ability of passive and active stabilizers in the lumbo-pelvic region to maintain appropriate trunk and hip posture, balance and control during both static and dynamic movements". ${ }^{2}$ Because of this, core stability, has been defined as the ability to control the position. ${ }^{3}$ More specifically the transverse abdominus, internal obliques, external oblique's, quadratus lumborum, multifidus, rotatores, and rectus abdominus are the focus muscles for core stability. ${ }^{4,5,6,7}$ These specific muscles also incorporate the serape effect. ${ }^{14}$ Core is the connector from lower to the upper body; it also works to transfer the energy for many sports. ${ }^{14}$ The core is thought to initiate movement and provide a stable base for the extremities. ${ }^{12}$ Prior to a movement of the upper extremity the transverse abdominus activates within $\mathbf{3 0}$ milliseconds. For the lower extremity it will activate 110 milliseconds before the leg moves. ${ }^{13}$ The movement starts proximal to the torso and moves distally to the extremities. ${ }^{5}$ For this reason there is a belief that a stable and a strong core will decrease the rates of injury, specifically low back pain. ${ }^{1,16}$

In order to understand the concepts explained further the anatomy and biomechanics of the core should be identified. There are two different muscle regions. Global muscles are primary movers that have no direct attachment to the spine. ${ }^{8}$ These specific muscles would be rectus abdominus and erector spinae, which consist of larger muscle groups. There are also a group of muscles referred to as local muscles. These muscles are known for maintaining posture and are considered stabilizing muscles due to the proximity to the axis with direct attachments. ${ }^{8}$ These muscles are the transverse abdominus, 
multifidus, rotators, internal and external obliques. The transverse abdominus (TA's), the deepest abdominal muscles, run horizontally and connect to the lumbar fascia. ${ }^{9,10,11}$ The TA's have a direct relationship to anticipating movement or perturbation with balance, for this reason it's thought to have a positive effect on decreasing injury rates. ${ }^{11}$

Core stability is usually evaluated with either McGill's endurance testing or Sahrmann core testing. Other sources $4,16,17,18,19$ evaluated a link with training the core and performance. Measurements were taken on subjects using McGill's endurance testing, ${ }^{15}$ the Functional movement screen (FMS), ${ }^{21} 1 \mathrm{RM}$ bench, ${ }^{20}$ or squat, ${ }^{20} 10$ yard shuttle run, ${ }^{20}$ functional performance throwing index, ${ }^{19}$ and vertical jump. ${ }^{20}$ Many times the relationship was not correlated between core and functional testing. This may be due to not having a comprehensive training program. Few reliability studies on various tests are evident in the literature. ${ }^{5}$ The quadruped arm raise test was used in Liemohn's study. Liemohn ${ }^{22}$ used a stability platform where the test was scored by the number of seconds that balance was maintained. They found that this test should be considered a sound test to evaluate core stability. ${ }^{22}$ The downfall with a test that uses a stability platform is that the instrument is not available to all athletic trainers. Further, Hibbs et al. ${ }^{9}$ stated that there is no gold standard for the assessment of core stability. Another reliability study looked at front and side abdominal power tests. ${ }^{23}$ There was an ICC value of 0.95 for front abdominal power tests (FAPT) and 0.93 for the side abdominal power test (SAPT) that resulted in excellent test-retest reliability. To assess the power component of the core these two abdominal power tests may be used. ${ }^{23}$ The two power tests and the quadruped arm raise tests are a few evaluation tools that have been tested for reliability and has the ability to be performed easily in the field.

Overall, core stability is an area that many Physical Therapists (PT's), Athletic Trainers (AT's) and strength coaches believe is important, but the degree of importance has not yet been determined. Core 
stability has been thought to increase performance while also decreasing injury rates, neither of these statements have been evident in the literature. Furthermore, there is no standard way to evaluate the core, and there are several different factors that affect injury rates and performance. It is important to evaluate local stabilizing muscles like the TA's. There have been studies that evaluated core power or used sophisticated laboratory equipment to test reliability of field tests. Therefore, a measurement technique that is applicable for the clinical athletic trainer is paramount, especially for baseball athletes. As core stability had been advocated for sports activities, especially baseball, it is simply not the answer but a piece of the puzzle, and is a tool that is used in the testing and training of athletes. Functionally during a throwing motion with baseball athletes, there is a point when an unstable or single leg position is evident. This is when the importance of core falls into play. As core is the ability to maintain postural positioning and assist in the transfer in energy, baseball players need the ability to maintain a stable position when on a single leg but also need a good transfer of energy from lower body through the core and scapula down to the shoulder and arm for a strong throw. ${ }^{26}$ Thus, the following research questions are asked:

\section{Research Questions}

1. Are there functional tests reliable to baseball?

2. Are there core stability tests reliable to baseball?

3. Are there dynamic stability tests reliable to baseball?

4. Will the Sahrmann lower abdominal test achieve acceptable ICC scores?

Experimental Hypothesis

1. The Sahrmann lower abdominal test was reliable.

2. The test will have high ICC values and be similar between weeks.

3. The SEM value will be low for the measurements. 


\section{Assumptions}

1. All athletes will meet the inclusion criteria for the research study.

2. The functional testes used will be reliable

3. The documentation of each athlete's testing scores will be accurate.

4. Each week the test will be administered following identical procedures.

5. The same test will be used each week.

6. All athletes will listen to directions and perform the test to the best of their ability.

7. The core evaluation tests used are valid and reliable.

Delimitations

1. Subject population is not generalizable to the normal population. Subject population is specific to Division II male baseball players.

2. Participants were between the ages of $18-24$

3. The internal factors of each subject cannot be controlled: health, nutrition, weight training, etc.

Operational Definitions

1. Core endurance- The ability of the muscles that control movement and stabilize the lumbar spine to hold a contraction. ${ }^{38}$

2. Core stability- "The ability of passive and active stabilizers in the lumbo-pelvic region to maintain appropriate trunk and hip posture, balance and control during both static and dynamic movements" . ${ }^{2}$

3. Core strength- The ability of the core to generate and maintain force. ${ }^{2}$

4. Lumbo-pelvic region- Another word for core or the trunk, but specifically the lumbar and pelvis region. ${ }^{38}$

5. Passive subsystem -Is comprised of spinal ligament and facet articulations, will only allow the spine to support a load of about $10 \mathrm{~kg} .{ }^{8,38,42,41}$

6. Spinal neutral- The midrange position between lumbar flexion and extension. ${ }^{13}$

7. Active subsystem- Comprised of muscles which are divided into local and global, helps with the "ability to create extremity movement without compensatory movement of the spine or pelvis." 38 
8. Global muscles- Primary movers that have no direct attachment to the spine. ${ }^{8}$

9. Local muscles- Maintain posture and are considered stabilizing muscles due to the proximity to the axis with direct attachments. ${ }^{8}$

10. Kyphotic Posture- Sternocleidomastoid, upper trap, and pectoralis muscles are shortened. ${ }^{47}$

11. Upper crossed/ Lower crossed- Present with forward head, overly kyphotic thoracic spine, and anteriorly rotated pelvis. ${ }^{47}$

12. Abdominal bracing- Lateral flaring of the abdominal wall. ${ }^{1}$

13. Serape effect- Is the idea that to reinforce the muscles of the core that act as connectors. There is a diagonal pattern that allows the core to take full advantage of the rotational patterns of the cores function. $^{8}$

14. Automatic reorganization- This occurs when there is a perception or a threat of pain. Exercises will help normalize motor control which includes timing dysfunction to avoid injury. ${ }^{11}$

15. "Level Belt"- A clinical tool that was designed to measure lumbo-pelvic control in a functional upright position. ${ }^{26}$

16. Neuromuscular training program- A program that emphasizes plyometrics in combination with biomechanical feedback and technique training. ${ }^{62}$

Limitations

1. Participant can drop out of the study at any time.

2. External validity will exist due to the study not being generalizable to other baseball participants.

3. An external validity will exist from the subject population and the choice of participants.

4. Participants may not perform $100 \%$ effort for each test.

Significance of Study

Core stability has been an area of focus for strength coaches, physical therapists and athletic trainers for years now. The downfall of core stability is that there is no field test that clinicians or strength coaches can use to determine "at risk" individuals that have a weak core. Along with limited identifiable tests there is very little research on the specifics of core that relate to individual sports, such as baseball. It is not known if baseball players need core endurance, strength or stability. Due to the throwing and hitting 
mechanics, baseball has a strong correlation between the need for stability and power. The core acts as a link between the force exchange and maintaining stability during the early cocking phase of a pitch or throw along with contact with the ball during batting. This link helps direct the power from the legs and hips up the kinetic chain into the throwing arm and eventually the baseball. It also allows the athlete to stand on one leg in a stable position. This study will help determine the reliability of functional, core and dynamic stability tests as they relate to baseball athletes. Functional tests are created in order to help bridge the gap between rehabilitation and sports specific activities. Often time's athletes that are focusing on functional activities are working back to activity. A reliable standard is needed for these tests in order to facilitate equal and accurate testing. Determining the reliability of these tests will not only benefit the athlete but the Athletic Trainers, coaches, and strength coach. This study will contribute to the body of knowledge by determining a field test for core stability that athletic trainers, strength coaches and physical therapist can perform with little equipment. In turn, determining a test for a group of athletes will help these individuals establish a means to screen "at risk" individuals.

Once this study is completed it is important to disseminate the information. This is important to help the athletic training, and strength coach community better serve their patients and athletes. Due to the minimal research specific to baseball and evaluating screening tools this could advance rehabilitation and screening of baseball athletes. The research will be presented at workshops, in classes around the community, and incorporated into in-services. 


\section{APPENDIX B}

\section{LITERATURE REVIEW}

Introduction

Core stability is defined as stable and dynamic stability of the body during functional activities. Stability is important for all athletes but specifically overhead athletes like baseball players. Baseball players are often in unstable positions such as one legged, changing directions, but also transferring energy between lower and upper body; which all incorporates the core. The core assists to control spinal loading, ${ }^{41}$ anticipatory movements of extremities ${ }^{38}$ and transfer energy from lower extremity through the core to upper extremities. The core is the foundation of the body; the muscles of the core influence the position of the pelvis and help create correct movements. ${ }^{24}$ There are two types of core muscles; the global and local muscles that both comprise specific muscles. ${ }^{9,24,43}$ A good rule of thumb is local muscles are smaller, deeper, stabilizing muscles, however, global muscles are larger, superficial, and mover muscles. ${ }^{8}$ (Refer to Table B1 for muscles origins, insertions, actions and innervations) Local muscles are: Psoas, quadrates lumborum, lumbar multufidus, internal oblique, transverse abdominus ${ }^{8}$, rotators, interspinalis, intertransversalis. ${ }^{15,38}$ Global muscles are: rectus abdominus, external obliques ${ }^{8}$ , rectus femoris, sartorius, iliacus, psoas major, minor, gluteus maximus, semimembranosus, semitendonosus, long head of the biceps femoris, adductor magnus, adductor brevis, adductor longus, gracilis, pectineus, tensor fascia latae, gluteus medius, gluteus minimus. ${ }^{15,38}$ Many injuries are common from a weakened, unbalanced, faulty core. Low back injuries are the most common, these injuries often present with having delayed contraction of transverse abdominus. ${ }^{9,10,16}$ Maintaining lumbar stability will stabilize the spine and create functional stability. ${ }^{45}$ Research on core stability is minimal. There are a few studies that have evaluated the reliability of different exercises. ${ }^{3}$ During this literature review core is defined; the anatomy and biomechanics of the core, the relationship to baseball and the measurements of the core that are used most often in studies was focused on. 


\section{Definition of Core Stabilization}

Core is an area of the body that is comprised of passive and active structures such as bone, musculature, and ligaments of the spine and hips. ${ }^{2,8,22,42,41}$ The core is also referred to as the lumbopelvic hip complex due to the inclusion of structures from the lumbar and pelvic region. ${ }^{18}$ Specifically the passive subsystem is comprised of spinal ligaments and facet articulations. ${ }^{8,24,42,41}$ These structures only allow the spine to support a load of about $10 \mathrm{~kg}$, which is far less than body mass. ${ }^{38}$ The active subsystem is comprised of the muscles which are divided into local and global sections "22, 38 "the ability to create extremity movement without compensatory movement of the spine or pelvis." ${ }^{46}$ One source defined core stability as "the ability of passive and active stabilizers in the lumbo-pelvic region to maintain appropriate trunk and hip posture, balance and control during both static and dynamic movement." $\quad 2,38$ Core stability helps to enhance dynamic stability. ${ }^{44}$ The body attempts to maintain stability when there are perturbations. ${ }^{2,23}$ In addition, the core is directly involved in the production, transfer and control of force and motion from proximal to distal segments. ${ }^{48}$ Over the past decade the core has been focused on for injury prevention along with performance enhancement, with no solid evidence to determine significant correlation to either with collegiate or professional athletes. ${ }^{2}$ However, there has been some high-quality research in determining how low back pathologies may be related to weakened core stability. Core stability can be explained to maximize efficient athletic function. To obtain function the coordination of the activation should place the distal segment in the most efficient position at the right velocity and time. Therefore, this will produce the required athletic task. ${ }^{5}$ It is assumed that core training is to help prevent injuries, improve performance, and treat lower

back injuries. ${ }^{48}$ However, the evidence supporting these ideas are contradictory and lacking. ${ }^{48}$

Training the core is heterogeneous. There are multiple philosophies about the correct way to train the core, with very little conclusive research to actually determine the best philosophy. This is 
more apparent when looking at performance or injuries, as there are so many factors and to increase and decrease these aspects of training should be considered.

Anatomy, Physiology and Biomechanics of Core

Table B1. Local and Global Muscles ${ }^{47}$

\begin{tabular}{ll}
\hline Global muscles-prone to shortness/tightness & Local muscles-prone to lengthen/weakness \\
\hline Rectus abdominus & Gluteus medius and maximus \\
Erector spinae & Transvers abdominus \\
Illiopsoas & Multifidus \\
Suboccipitals & Deep neck flexors \\
Levator scapulae & Lower trapezius \\
Lateral fibers external obliques & Internal obliques \\
Adductors of the thigh & Serratus anterior
\end{tabular}

The local and global muscles both have differing functions. ${ }^{49}$ Global muscles are typically fasttwitch fibers that have long levers and large moment arms that can create and output large amounts of forces, torque, speed and power. ${ }^{13}$ The deep layer or local muscles are known for stabilizing the spine. ${ }^{13,47}$ These muscles are also kept in check by the central nervous system to provide feedback about the joint position. ${ }^{13,43}$ The Central Nervous System (CNS) has the ability to plan the muscle activity in advance of the movement to prepare the spine for the loads. ${ }^{10}$ These plans are delivered to the muscles via the innervations (Table B2). Local muscles control the intersegmental motion between adjacent vertebra and influence intra-abdominal pressure to help spinal stability, ${ }^{10,24,47,50}$ while the global muscles are known for transferring forces and energy. ${ }^{24}$ Certain muscles of the core seem to become short and tight, while other muscles tend to lengthen and become weakened (Table B1). ${ }^{47}$ When an athlete has overactive global muscles and underactive local muscles the shortening and lengthening becomes exaggerated. ${ }^{47}$ When these imbalanced muscles patters happen outward signs include a forward head, kyphotic posture, and anteriorly rotated hips. ${ }^{47}$ This is known as the upper crossed or lower crossed syndrome, and is becoming very prevalent in today's society. ${ }^{47}$ In order to 
correct these imbalances not only does a stretching program need to be followed to help mobilize this athlete, but strengthening in order to continue to keep the athlete balanced. ${ }^{47}$

Contrary to the classifications used by most; there are some that are rethinking this concept. ${ }^{39}$

The concept of classifying takes into account only the muscles in isolation, but lacks the intricate

function as a system. ${ }^{39}$ The relationship many muscles have with structures like the fascia can make this classification blurry. Stevens et al ${ }^{39}$ has suggested that tension to the fascia may contribute to limitations in the joint while also stiffening the lumbar spine and sacroiliac joint, but still allowing forces to be transferred between the trunk and limbs. ${ }^{39}$ The fascia tension can help to control the spinal segments by helping to increase intra- abdominal pressure as well. ${ }^{10}$

Table B2. Muscles of the Core. ${ }^{51,52}$

\begin{tabular}{|c|c|c|c|c|}
\hline Muscles & Origin & Insertion & Action & Innervations \\
\hline Illiocoastalis & $\begin{array}{l}\text { Spinous process of } \\
\text { lumbar } 11,12, \\
\text { thoracic vertebrae, } \\
\text { posterior part of } \\
\text { medial lip of iliac } \\
\text { crest, suprapinous } \\
\text { ligament, and } \\
\text { lateral crests of } \\
\text { sacrum }\end{array}$ & $\begin{array}{l}\text { Inferior boarders of } \\
\text { angles of lower six or } \\
\text { seven ribs }\end{array}$ & $\begin{array}{l}\text { Extension of vertebral } \\
\text { column }\end{array}$ & $\begin{array}{l}\text { Posterior primary } \\
\text { divisions of the spinal } \\
\text { nerves }\end{array}$ \\
\hline Longissimus & $\begin{array}{l}\text { Posterior surfaces } \\
\text { of transverse } \\
\text { process }\end{array}$ & $\begin{array}{l}\text { Into tips of transverse } \\
\text { process of all thoracic } \\
\text { vertebrae, lower } 9 \text { or } 10 \\
\text { ribs }\end{array}$ & $\begin{array}{l}\text { Extension and lateral } \\
\text { flexion }\end{array}$ & $\begin{array}{l}\text { Posterior primary } \\
\text { divisions of the spinal } \\
\text { nerves }\end{array}$ \\
\hline $\begin{array}{l}\text { Spinalis } \\
\text { thoracis }\end{array}$ & $\begin{array}{l}\text { Tendons from } \\
\text { spinous process of } \\
\text { first two lumbar } \\
\text { and last two } \\
\text { thoracic vertebrae }\end{array}$ & $\begin{array}{l}\text { Spinous processes of } \\
\text { upper eight thoracic } \\
\text { vertebrae }\end{array}$ & $\begin{array}{l}\text { Extension of vertebral } \\
\text { column }\end{array}$ & $\begin{array}{l}\text { Posterior primary } \\
\text { divisions of the spinal } \\
\text { nerves }\end{array}$ \\
\hline $\begin{array}{l}\text { Quadratus } \\
\text { lumborum }\end{array}$ & $\begin{array}{l}\text { Posterior inner lip } \\
\text { of the iliac crest }\end{array}$ & $\begin{array}{l}1 / 2 \text { length lower boarder } \\
\text { of the } 12^{\text {th }} \text { rib and } \\
\text { transverse processes of } \\
\text { upper } 4 \text { lumbar } \\
\text { vertebrae }\end{array}$ & Lateral flexion & $\begin{array}{l}\text { Posterior Primary } \\
\text { divisions of the spinal } \\
\text { nerves }\end{array}$ \\
\hline $\begin{array}{l}\text { Rectus } \\
\text { abdominus }\end{array}$ & $\begin{array}{l}\text { Pubic } \\
\text { crest/symphysis }\end{array}$ & $\begin{array}{l}\text { Costal cartilage of 5-7 } \\
\text { ribs }\end{array}$ & Trunk flexion & Ventral Rami \\
\hline $\begin{array}{l}\text { Internal } \\
\text { obliques }\end{array}$ & $\begin{array}{l}\text { lateral } 2 / 3 \text { of } \\
\text { inguinal ligament }\end{array}$ & $\begin{array}{l}\text { Crest of pubis and 10-12 } \\
\text { ribs }\end{array}$ & $\begin{array}{l}\text { Trunk flexion, lateral } \\
\text { flexion }\end{array}$ & $\begin{array}{l}\text { Illiohypohastric } \\
\text { Illioinguinal }\end{array}$ \\
\hline
\end{tabular}




\begin{tabular}{|c|c|c|c|c|}
\hline & & & & Ventral rami \\
\hline $\begin{array}{l}\text { External } \\
\text { obliques }\end{array}$ & $5-8$ ribs & $\begin{array}{l}\text { Anterior superior iliac } \\
\text { spine }\end{array}$ & Rotation, trunk flexion & $\begin{array}{l}\text { Illiohypohastric } \\
\text { Illioinguinal } \\
\text { Ventral rami }\end{array}$ \\
\hline Transverse & $\begin{array}{l}\text { Lower } 6 \text { ribs, lateral } \\
1 / 3 \text { inguinal } \\
\text { ligament, lip of iliac } \\
\text { crest }\end{array}$ & Linea alba, pubic crest & $\begin{array}{l}\text { Stabilization, holds } \\
\text { internal organs in. }\end{array}$ & $\begin{array}{l}\text { Thoracoabdominal } \\
\text { nerves (anterior rami } \\
\text { of T6-^12 spinal } \\
\text { nerves) and first } \\
\text { lumbar nerve }\end{array}$ \\
\hline Multifidus & $\begin{array}{l}\text { Lumbar region: } \\
\text { Superior aspect of } \\
\text { sacrum } \\
\text { Thoracic region: } \\
\text { Transverse } \\
\text { processes } \\
\text { Cervical region: } \\
\text { Articular processes }\end{array}$ & Spinous process & $\begin{array}{l}\text { Bilateral contraction: } \\
\text { Stabilization of } \\
\text { vertebral column } \\
\text { Unilateral } \\
\text { contraction: Rotation } \\
\text { of the spine to the } \\
\text { opposite side }\end{array}$ & $\begin{array}{l}\text { Posterior primary } \\
\text { divisions of the spinal } \\
\text { nerves }\end{array}$ \\
\hline Rotatores & Transverse process & $\begin{array}{l}\text { Spinous process of the } \\
\text { vertebra immediately } \\
\text { above the origin }\end{array}$ & $\begin{array}{l}\text { Bilateral contraction: } \\
\text { extension of spine, } \\
\text { Stabilization of } \\
\text { vertebral column } \\
\text { Unilateral } \\
\text { contraction: Rotation } \\
\text { of the spine }\end{array}$ & $\begin{array}{l}\text { Posterior primary } \\
\text { divisions of the spinal } \\
\text { nerves }\end{array}$ \\
\hline $\begin{array}{l}\text { Gluteus } \\
\text { Maximus }\end{array}$ & $\begin{array}{l}\text { Posterior gluteal } \\
\text { line of ilium, } \\
\text { posterior sacrum, } \\
\text { posterior coccyx }\end{array}$ & $\begin{array}{l}\text { Gluteal tuberosity of } \\
\text { femur, through a fibrous } \\
\text { band to the iliotibial } \\
\text { tract }\end{array}$ & $\begin{array}{l}\text { Hip extension, hip } \\
\text { external rotation, hip } \\
\text { adduction }\end{array}$ & Inferior gluteal \\
\hline $\begin{array}{l}\text { Gluteus } \\
\text { medius }\end{array}$ & $\begin{array}{l}\text { External surface of } \\
\text { superior ilium, } \\
\text { anterior gluteal } \\
\text { line, gluteal } \\
\text { aponeurosis }\end{array}$ & $\begin{array}{l}\text { Greater trochanter of } \\
\text { femur }\end{array}$ & $\begin{array}{l}\text { Hip abduction } \\
\text { Anterior fibers: Hip } \\
\text { flexion, Hip internal } \\
\text { rotation } \\
\text { Posterior fibers: Hip } \\
\text { extension, Hip } \\
\text { external rotation }\end{array}$ & Superior gluteal \\
\hline $\begin{array}{l}\text { Gluteus } \\
\text { minimus }\end{array}$ & $\begin{array}{l}\text { Lower portion of } \\
\text { ilium, margin of } \\
\text { greater sciatic } \\
\text { notch }\end{array}$ & $\begin{array}{l}\text { Greater trochanter of } \\
\text { femur }\end{array}$ & $\begin{array}{l}\text { Hip abduction, hip } \\
\text { internal rotation, hip } \\
\text { flexion }\end{array}$ & Superior Gluteal \\
\hline
\end{tabular}

As with any function there is a correct way the body works and an incorrect way. When the

body works ineffectively there are injuries and pain that occur. Biomechanical research has shown that joint dysfunction anywhere in the body can lead to compromise up or down the kinetic chain. ${ }^{13}$ Most commonly with imbalances in the core there is low back pain. ${ }^{9,10,42,41,53}$ When there are imbalances 
there is evidence of abnormal spinal loading that contributes to low back pain. ${ }^{40}$ Imbalances can include delayed activation, decrease in number of muscles firing, or delayed latency of the core muscles. ${ }^{40}$ When the core is functioning normally the central nervous system will activate the trunk musculature, specifically the Transverse Abdominus ( TrA's) first, before a movement to provide a stable base for the body to work from. ${ }^{10,23,54}$ The typical motor response will be compromised with a delay in activation in those with low back pain. ${ }^{53}$ Normal functioning of the core is to prevent motion rather than increasing motion. ${ }^{55}$ There is research that supports the concept of local and global muscles firing as one, agreeing with the concept of an intricate system that functions as a whole. ${ }^{9,11,39,24,55,56}$ To achieve spine stability all muscles need to contract as one to stiffen and stabilize the spine. ${ }^{55}$ It has been thought that with exercises such as the quadruped position trains the stabilizers to fire, but some believe that there are stabilizing muscles working, but the global muscles are also working collectively. ${ }^{24}$ McGill ${ }^{15}$ has confidence that "core stability is a dynamic concept that continually changes to meet postural adjustments or external loads accepted by the body. This suggested that to increase core stability, exercises must be performed that stimulate the movement patterns of a given sport." ${ }^{15}$ Arokoski ${ }^{56}$ had subjects perform an array of exercises prone, supine, seated and standing. These exercises showed that the local and global muscles were firing similar patterns throughout the motions. This completes the idea that local muscles cannot be trained separately, while global and local muscles function together as one. Another idea is that in order for global muscles to fire correctly the local muscles need to be trained to fire first or to be trained to fire constantly. This idea helps to support the fact that local muscles can be trained separately. ${ }^{39}$ Many of the local and global muscles are intricately connected through a fascia or a common origin or insertion point; note the proximity of origins and insertions (Table B2). ${ }^{39}$ Urquhart ${ }^{1}$ agues this point of a specific muscle recruitment pattern during different abdominal movements such as inward movement of the lower abdominals, abdominal bracing and posterior pelvis tilt. The transverse abdominus was $70 \%, 100 \%$, and $65 \%$ more active according to the 
EMG than the oblique inturnus, oblique externus and rectus abdominus, respectively during the inward motion of the abdominal wall. ${ }^{1}$ When abdominal bracing was researched there was greater oblique externus activity compared to the transverse abdominus, oblique internus, and rectus abdominus. ${ }^{1}$ In comparison to the other muscles, with the posterior pelvic tilt the oblique internus saw the most activity. ${ }^{1} \mathrm{McGill}{ }^{55}$ considers the abdominal bracing is best because it does activate all the musculature together and one muscle will not enhance stability alone. Noting the differences with distinctive "bracing" techniques allows the study of activity and firing pattern comparison but is also controversial.

Not only are the abdominal muscles important for core stability. There are many other muscles surrounding the lumbo-pelvic complex that should not be over looked. ${ }^{10}$ For example the hamstrings, originate on the ischial tuberosity (Table B2) and affect the pelvic complex. The hamstrings are known for a phasic role in stabilizing the pelvis, specifically during standing and the stance phase of gait. ${ }^{57}$ Not only do the hamstrings allow this to occur but the gluteals and the abdominal muscles aid in the stabilization. ${ }^{57}$ This is where the importance of local and global muscles occurs. As there are multiple muscles, it is not just about one muscle but specifically about the muscles working properly and together. During injury that interrupts the proper working of the muscles. This is shown often in low back pain. The onset of gluteus maximus and biceps femoris during the swing phase, while walking on a treadmill, was activated earlier than with an injury free control group. Thus, with individuals with pelvic pain or low back pain, the hamstrings have an early activation and increased amplitude, which is not the normal pattern. ${ }^{57}$ In this same population of individuals with injury there is a decreased activity of the transvers abdominus, which also could lead to sacroiliac joint pain. ${ }^{57}$ Another culprit for inhibiting the stabilizers and gluteals is the iliospoas. ${ }^{13}$ When the psoas is tightened or shortened, which is commonly seen in baseball athletes due to their typical posture, the local muscles and gluteus maximus are inhibited. ${ }^{13}$ It has been identified that subjects with hypermobility and a history of sprained ankles have a delayed activation of the gluteus medius on the same side as the unstable ankle. ${ }^{54}$ The importance of 
all these muscles is that the spinal load is transferred via the sacroiliac joint and further into the legs.

${ }^{58}$ The transvers abdominus helps stabilize not only the trunk but the sacroiliac joint due to this horizontal pattern as shown with origin and insertion (Table B2). This allows for the muscle to decrease the vertical sheer forces. ${ }^{58}$ This further supports the idea that the kinetic chain is intricately connected and works as a whole for performance and injury prevention. ${ }^{58}$

Core stability exercises improve the function of the muscles that are used to increase trunk stability and when these muscles are functioning optimally they will protect the athlete from injuries; especially to the spine. ${ }^{39}$ Hodges and Richardson ${ }^{10}$ inspected the sequence of muscle contractions compared to limb movement. It has been found that the core stabilizers (TrA, multifidus, rectus abdominus and obliques) contract prior to any limb movement. ${ }^{4}$ It has been noted that there is a contraction 30 milliseconds before movement of the shoulder and 110 milliseconds before leg movement, ${ }^{13}$ supporting the theory that the TrA are contracted well before in anticipation of perturbation to maintain stability. ${ }^{5,11}$ This has consistently lead to specialists assuming that any delay in onset timing is subject for disaster and specifically low back pain. ${ }^{10}$ Significant delays can be about 20 milliseconds. ${ }^{10}$ After this there was an idea that athletes should be taught to continuously contract the local stabilizers. ${ }^{59}$ The idea behind this was that if the core is continuously contracting it will constantly be stable therefore; there should be no need to worry about the sequence or onset. The body would have an automatic reorganization of the neuromuscular system to avoid injury. ${ }^{11}$ Although this may be the case initially, to restore normal function the re-education of the whole muscle system should be incorporated. ${ }^{1}$ Integrating the total body will also allow for additional training specific to sport events. A pre-programmed muscle activation pattern is best to describe core stability. ${ }^{5}$ This also supports the above thoughts by Lederman, ${ }^{11}$ Hodges and Richardson, ${ }^{10}$ and Okada. ${ }^{4}$ The body's muscle activation pattern is proximal stability for distal mobility. ${ }^{4,5}$ One study demonstrated that there is greater consistency in the muscle activation pattern with those who could better control their lumbar- 
pelvic motion, keeping it in neutral. ${ }^{42}$ This was detected using reflective tape and a video camera. ${ }^{42}$ "Twenty-six percent more activation can occur in the ankle as a result of proximal muscle activation." 5 Rehabilitation literature has shown that balance training has reduced the incidence of ankle sprains in a group of volleyball girls. ${ }^{42}$ The core is made up of the spine, hips, and pelvis, proximal lower limbs and abdominal segment. ${ }^{5}$ Generation of force and transferring that force are also functions of the core in addition to the main function of stability. ${ }^{5,20,12}$ The thoracolumbar fascia is the structure that is mainly responsible in the transfer of energy. ${ }^{5}$ The fascia connects the gluteus maximus (lower limb) to the latissimus dorsi (upper limb).

${ }^{5}$ There has been statements that the core is stabilized by a co-contraction with the muscles of the back and hips, ${ }^{6}$ forming a "hoop" around the abdomen consisting of the muscles that works to support the core. ${ }^{5,13,50}$ Hibbs $^{9}$ believe that the core is comprised of a double walled cylinder, because of the diaphragm and the pelvic floor acting as a top and bottom to the cylinder. The relationship is apparent between the trunk and lower extremity movement. ${ }^{7}$

The core has a complex anatomy, physiology and biomechanics. Overall, the cores main goals are to stabilize, and transfer energy. There are many different thoughts and models for the biomechanics of the core, but one thing seems to be certain, baseball players need a strong core. Baseball athletes not only need to be stable but need a strong core to assist in transferring energy from lower body to upper body.

What is Measured?

"The ability to produce and maintain a balance between mobility and stability along the kinetic chain while performing fundamental patterns with accuracy and efficiency" is the definition of functional movement according to Okada et al. ${ }^{4}$ The idea behind strengthening the core has been not only to decrease injury and low back pain, but to increase functional movement and sports 
performance. There has been an array of studies focusing on performance measures, proprioception measures, and core stability (Table B3 \& B4). ${ }^{4,16,17,18}$

Core can be defined by endurance, strength, or stability. Often time's endurance is thought of as the McGill's tests, which consist of trunk flexion, trunk extension, and lateral plank to both sides, this test is done by the subject holding the position until failure. ${ }^{4}$ Core strength is most often measured with an explosive test like the front and side abdominal power tests. The subject was instructed to lie back on the mat, arms alongside, knees bent with feet a hip distance apart. ${ }^{23}$ Then the subject kept arms locked out and created a sit up type motion, driving the medicine ball powerfully forward using the abdominals. ${ }^{23}$ However, core stability is usually thought of with the Sahrmann core stability test which consists of 5 levels increasing in difficulty. ${ }^{17}$ There are ways to evaluate the core indirectly; the single leg squat is a great example. It's been shown to significantly correlate to other core stability measures. Most often single leg squat is used to identify lower leg endurance but the stability of the core still needs to be initiated to stabilize the upper body. ${ }^{4}$ Exercises such as the bird dog that are performed in the quadruped position are also presented in the literature. ${ }^{39}$ This allows for a low-load non-anti-gravity posture with a neutral spine to maintain good balance. ${ }^{39}$ All stability exercises are aimed to optimize function of the trunk muscles that are believed to control stability. ${ }^{39}$ However, these are controversial tests that have little research to support them. The researcher has not come to an agreement with regards to a reliable and reproducible test to measure the core. ${ }^{5}$

Often, attempts to make connections between core stability and performance or strength measures are used. Nesser 2008 et al. ${ }^{16}$ found that core is moderately related to performance and strength. However, when referenced with the functional movement screen (FMS), there was no significant correlation between the core and the FMS. Another study that evaluated 1 RM (repetition maximal) bench press, and 1RM squat, countermovement vertical jump, 40 yard sprint and 10 yard shuttle run was compared to McGills core endurance testing there were no significant correlations 
identified. ${ }^{20}$ Core stability should be a priority for all sports conditioning, many of the traditional exercises used today can be modified to incorporate core stability challenges. ${ }^{38,42}$ This may be as simple as doing a lift on one leg, or cables and medicine balls can be involved with rotational exercises to become sports specific. ${ }^{38,42}$ The downside with combining these two activities is that each athlete may not be lifting heavy weights due to the need for stability. ${ }^{42}$ However, low load training helps to improve the CNS to control muscles coordination. ${ }^{9}$ Although this research is not specific to the topic of this study, it is important to understand the research that is already out there. There are controversial thoughts as to what types of core is needed for performance enhancement and injury prevention. It has been shown that core strength and power seem to be impractical with sports related performance, however, core endurance seems to be beneficial for injury prevention. ${ }^{38}$ There is an abundance of investigations with performance measures and core stability. However, there has been mixed results in the literature to find significant correlations with performance and core stability. ${ }^{9,48}$ Measurement Techniques

There is very little research that is conclusive about core stability especially with healthy subjects. There has been a plethora of research that has shown positive effects on patients with low back injuries and in helping to decrease lower body injuries (Table B4). Common core stability measures that have been used in the past are endurance and isokinetic measures of strength and work. ${ }^{23}$ Another measurement that is seen very little is measuring the contraction of the Transversus abdominus with an ultrasound machine. ${ }^{61}$ This may be considered close to a gold standard for measuring the transverses abdominus, although one has not been determined. A very recent study used an instrument designed to measure the amount of displacement from spine neutral during a single leg stance. ${ }^{26}$ The instrument is called the "Level belt", which helps to estimate a subject's ability to maintain pelvic neutral while shifting from a double leg stance to single leg. The deviations were compared to the pitching statistics such as innings pitched (IP), batting average against (BAA), strike outs per inning (BBin), walks plus hits 
per inning pitched (WHIP) and strikeouts per inning. ${ }^{26}$ Subjects that scored $>7^{\circ}$ on the level belt test had significantly fewer walks, plus hits per inning than subjects that scored $\leq 7^{\circ}$ and significantly more IP during the season. ${ }^{26}$ This study directly is related to performance in a sports specific sense. It shows the importance of core stability, especially in pitchers.

When determining the results of dynamic stability the Star Excursion Balance Test (SEBT) was evaluated. In a study by Filipa et al, ${ }^{62} 20$ uninjured soccer players participated in a neuromuscular training program that focused on core stability and lower extremity strength. The study showed that subjects increased their score compared to the control group that had no change on the SEBT scores. ${ }^{62}$ Another study evaluated the SEBT to normalize measurements. ${ }^{63}$ It was determined that there are no significant differences between gender for the SEBT. This was determined after using raw excursion measures, after the leg length was taken out of the equation. ${ }^{63}$

The McGills endurance test is used to measure core stability (Table B2). This test works under the assumption that if the global muscles are firing, the local have to be as well. Nesser et al. $2008,{ }^{16}$ tested Division I football athletes using McGills endurance tests along with other performance measures such as $40-$ yd sprint, power clean, shuttle run, etc. Nesser ${ }^{16}$ concluded that core stability is only moderately related to strength and performance measures. Nesser did more research but this time he used Division I female soccer players. He again compared core stability to different strength and power variables. There were no correlations between core stability strength, and power. ${ }^{16,12}$ Tse et al. ${ }^{64}$ researched performance measure with the McGills endurance test as well. The subjects were college age rowers divided into two groups; a core group or a control group. Tse et al. ${ }^{64}$ also assessed side plank and trunk extension and performance measure such as vertical jump, 40-meter sprint, overhead medicine ball throw. ${ }^{64}$ There was a significant improvement with the side bridging in the core group, but in the control group there was increased trunk extension, while no significant differences were found for the performance measures. ${ }^{64}$ Leetun et al ${ }^{6}$ also used the McGills core endurance testing. 
This author used a variety of male and female athletes from basketball and track. He compared core stability to hip abduction and external rotation strength. Males were found to produce greater hip abduction, external rotation and quadrates lumborum endurance measures (back extensor fatigue test). ${ }^{6}$ Overall, athletes that did not sustain an injury were significantly stronger in hip abduction and external rotation. ${ }^{6}$ This may suggest that there is a clear gender bias among female athletes. ${ }^{6}$ McGill ${ }^{15}$ studied the core stability endurance test to establish normative holding times. McGill used males and females that were all healthy. They only performed the McGills core stability endurance tests. Women had longer endurance times than men for torso extension, but not for flexion or side-bridge. ${ }^{15}$ The test was reliable with a coefficient of $>0.97$ for the repeated tests. ${ }^{15,12}$ Most importantly Lust et al ${ }^{19}$ used 19 Division III baseball athletes to measure an intervention using pre- and post- testing as the McGill endurance tests, and Functional Throwing-performance index. ${ }^{19}$ Although there was no significant difference between the two groups, there was an increase from pre-test to post-test. The increase ranged from $1.36 \%$ to $140 \%$.

Another prominent test that has been researched is exercises in the quadruped position. Stevens et al. ${ }^{39}$ used 30 healthy volunteers that performed 3 different exercises from the quadruped position. ${ }^{39}$ The greatest muscle activity was found with all three exercises. The muscles that were most active were the ipsilateral lumbar multifidus and gluteus maximus. ${ }^{39}$ The activity of the contralateral and ipsilateral external oblique muscles reached higher levels during single leg extension and the leg and arm extension. Also, with the leg and arm extension exercise there was greater muscles activity in all the back muscles, except for the latissimus dorsi. ${ }^{39}$ The research indicates that in all these exercises, healthy subjects hip and trunk muscles work together. ${ }^{39}$ Liemohn et al ${ }^{22}$ also used the quadruped position to test core stability. A stability platform prototype was made by Lafayette Instrument Co. Twenty-five university students were tested using the quadruped arm raise. The exercise was tested on four different days and the reliability coefficient for each was: day $1 ; 0.97$, day $2 ; 0.89$, day $3 ; 0.95$, and 
day $4 ; 0.92 .{ }^{22}$ It was determined for future research that 3 days will be needed to test because of the learning effect. ${ }^{22}$

Lastly, there is little research using the Sahrmann core stability test (Table B3). Stanton et al. ${ }^{17}$ worked on research measuring core stability by using the Sahrmann core stability test and the running economy of 18 male athletes. ${ }^{17}$ These 18 athletes participated in short term swiss ball training. ${ }^{17}$ Each athlete was tested pre- and post- the swiss ball intervention. Swiss ball exercises were done for two weeks, and there was no significant change in myoelectrical activity of abdominal or back muscles during the Sahrmann core stability test, treadmill $\mathrm{VO}_{2}$, running posture, or running economy. ${ }^{17}$ It is possible that swiss ball training has an effect on core stability. One would believe there would need to be more than two exercises done per week to receive a training affect. There is very little published data about the reliability of the Sahrmann core stability test, but there are many clinicians (Athletic Trainers) that use this model in their practice to pre-screen individuals for a weakened core. (C. Endicott, written communication 2013). The anecdotal evidence leans towards the use of the Sahrmann core stability test, but there is very little research done, with multiple interpretations of the levels. Another important article to note was Shirey ${ }^{25}$ this particular research was testing the different in women doing a single leg squat when split into a low core group and high core group based on the Sahrmann lower abdominal core stability test. The results are not as important as how the groups were decided. After each female, there were 14 healthy college women, was tested using the Sahrmann lower abdominal core stability test (referred to Sahrmann protocol/test) it was noted only five participants reached level 1 or 2 , while nine scored zero. ${ }^{25}$ In order to make low and high core groups the individuals with a score of zero were placed into the low core group and the others were placed in a high core group.

There are many different measures that are used to evaluate core stability. What needs to be completed is determining which tests are reliable and should be used to further research in determining cores relationship to injury, performance and function. To determine the reliability of one specific test, 
this thesis will focus on determining the test re- test reliability of the Sahrmann lower abdominal core stability test.

Table B3. Core Stability Literature Review

\begin{tabular}{|c|c|c|c|c|}
\hline Author & What measured & How measured & Instruments & Sports used \\
\hline $\begin{array}{l}\text { Okada T, Huxel K, } \\
\text { Nesser T }{ }^{4}\end{array}$ & $\begin{array}{l}\text { Core stability, } \\
\text { functional } \\
\text { movement and } \\
\text { performance }\end{array}$ & $\begin{array}{l}\text { McGill's endurance test, FMS, } \\
\text { Deep Squat, trunk-stability push } \\
\text { up, right and left hurdle step, in } \\
\text { line lunge, shoulder mobility, } \\
\text { active straight leg raise, rotary } \\
\text { stability, backward med ball } \\
\text { throw, t-run, and single leg } \\
\text { squat }\end{array}$ & N/A & $\begin{array}{l}28 \text { healthy } \\
\text { individuals } \\
\text { (males and } \\
\text { females) }\end{array}$ \\
\hline $\begin{array}{l}\text { Nesser T, Huxel K, } \\
\text { Tincher J, Okada T } \\
\text { }\end{array}$ & $\begin{array}{l}\text { Core stability and } \\
\text { performance }\end{array}$ & $\begin{array}{l}\text { 1RM bench, vertical jump20 } \\
\text { and } 40 \text { yard sprints, } 10 \text { yard } \\
\text { shuttle run, McGills endurance } \\
\text { tests }\end{array}$ & N/A & $\begin{array}{l}29 \text { Division I } \\
\text { football players }\end{array}$ \\
\hline Nesser T, Lee $W^{20}$ & $\begin{array}{l}\text { Core stability and } \\
\text { strength and } \\
\text { power variables }\end{array}$ & $\begin{array}{l}1 \text { RM bench and } 1 \text { RM squat, } \\
\text { Countermovement vertical } \\
\text { jump, } 40 \text { yard sprint, } 10 \text { yard } \\
\text { shuttle run, McGills }\end{array}$ & N/A & $\begin{array}{l}16 \text { division I } \\
\text { female soccer }\end{array}$ \\
\hline $\begin{array}{l}\text { Leetun D, Ireland L, } \\
\text { Willson J, } \\
\text { Ballantyne B, Davis } \\
1^{6}\end{array}$ & Core stability & $\begin{array}{l}\text { Hip abduction, External rotation } \\
\text { strength, abdominal muscle } \\
\text { function, back extensor, } \\
\text { Quadratus lumborum } \\
\text { endurance (McGills) }\end{array}$ & $\begin{array}{l}\text { Hand } \\
\text { dynamometer }\end{array}$ & $\begin{array}{l}80 \text { females } 60 \\
\text { males } \\
\text { intercollegiate } \\
\text { basketball and } \\
\text { track athletes }\end{array}$ \\
\hline $\begin{array}{l}\text { Stanton R, Reaburn } \\
P, \text { Humphries } B^{17}\end{array}$ & $\begin{array}{l}\text { Core stability and } \\
\text { running economy }\end{array}$ & $\begin{array}{l}\text { Stature, body mass, core } \\
\text { stability, EMG activity of } \\
\text { abdominal and back muscles, } \\
\text { VO2 Max,running economy and } \\
\text { running posture, Sahrmann } \\
\text { Core stability test }\end{array}$ & $\begin{array}{l}\text { Inflatable pad of } \\
\text { a stabilizer } \\
\text { pressure } \\
\text { biofeedback unit }\end{array}$ & 18 male athletes \\
\hline $\begin{array}{l}\text { Crowley P, } \\
\text { Swensen T }\end{array}$ & $\begin{array}{l}\text { Core stability vs. } \\
\text { injury }\end{array}$ & $\begin{array}{l}\text { Front and side abdominal } \\
\text { power test }\end{array}$ & Medicine ball & $\begin{array}{l}24 \text { untrained } \\
\text { women }\end{array}$ \\
\hline Yu J, Lee $\mathrm{G}^{23}$ & Core stability & $\begin{array}{l}\text { Pilates; lower extremity muscle } \\
\text { strength, postural stability }\end{array}$ & $\begin{array}{l}\text { Isokinetic } \\
\text { equipment, } \\
\text { balance device }\end{array}$ & 40 healthy \\
\hline $\begin{array}{l}\text { Liemohn W, } \\
\text { Baumgartner T, } \\
\text { Fordham S, } \\
\text { Srivatsan A }\end{array}$ & $\begin{array}{l}\text { Test reliability of } \\
\text { equiptment, core } \\
\text { stability }\end{array}$ & Quadruped arm raise & $\begin{array}{l}\text { Stability } \\
\text { platform }\end{array}$ & $\begin{array}{l}25 \text { university } \\
\text { students }\end{array}$ \\
\hline $\begin{array}{l}\text { Weir A, Darby J, } \\
\text { Inklaar H, Koes B, } \\
\text { Bakker E, Tol J }{ }^{22}\end{array}$ & Core stability & $\begin{array}{l}\text { Unilateral squat, lateral step- } \\
\text { down, frontal plane testing, } \\
\text { sagittal plane testing, } \\
\text { transverse plane testing, the } \\
\text { bridge }\end{array}$ & video & 40 subjects \\
\hline
\end{tabular}




\begin{tabular}{|c|c|c|c|c|c|}
\hline $\begin{array}{l}\text { Sharma A, } \\
\text { Geovinson S, } \\
\text { Sandhu J }\end{array}$ & $\begin{array}{l}\text { Core } \\
\text { strengthening, } \\
\text { trunk instability }\end{array}$ & \multicolumn{2}{|c|}{$\begin{array}{l}\text { Vertical jump, static balance } \\
\text { variables } \\
\text { i.e. double straight leg lowering } \\
\text { test, counter movement jump, } \\
\text { squat jump, spike jump, block } \\
\text { jump, wobble board }\end{array}$} & $\mathrm{N} / \mathrm{A}$ & $\begin{array}{l}40 \text { volleyball } \\
\text { players }\end{array}$ \\
\hline $\begin{array}{l}\text { Hodges } \mathrm{P} \text {, } \\
\text { Richardson } \mathrm{C}^{10}\end{array}$ & $\begin{array}{l}\text { Spinal } \\
\text { stabilization }\end{array}$ & \multicolumn{2}{|c|}{$\begin{array}{l}\text { Rapid shoulder flexion, } \\
\text { abduction, extension in } \\
\text { response to visual stimulus }\end{array}$} & EMG & 30 subjects \\
\hline $\begin{array}{l}\text { Stevens V, } \\
\text { Vleeming A, } \\
\text { Bouche K, Mahieu } \\
\text { N, Vanderstraeten } \\
\text { G, Danneels L }{ }^{39}\end{array}$ & Trunk stability & \multicolumn{2}{|c|}{$\begin{array}{l}\text { Single leg extension, leg and } \\
\text { arm extension, and leg and arm } \\
\text { extension in hip flexion, } 4 \text { point } \\
\text { kneeling position }\end{array}$} & EMG & 30 subjects \\
\hline $\begin{array}{l}\text { Saeterbakken A, } \\
\text { Van Den Tillaar R, } \\
\text { Seiler } \mathrm{S}^{18}\end{array}$ & $\begin{array}{l}\text { Core stability and } S \\
\text { effects on } \\
\text { throwing velocity }\end{array}$ & \multicolumn{2}{|l|}{ Sling exercise training } & Sling (like TRX) & $\begin{array}{l}24 \text { female } \\
\text { handball players }\end{array}$ \\
\hline 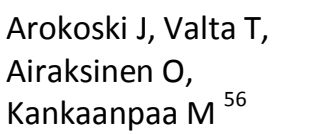 & Muscular control & \multicolumn{2}{|c|}{$\begin{array}{l}\text { Exercises in prone, bridged, } \\
\text { sitting and standing positions }\end{array}$} & EMG & 24 subjects \\
\hline $\begin{array}{l}\text { Konrad P, Schmits } \\
\text { K, Denner A }\end{array}$ & $\begin{array}{l}\text { Neuromuscular } \\
\text { activation }\end{array}$ & \multicolumn{2}{|c|}{$\begin{array}{l}\text { Array of gymnastics training } \\
\text { exercises: various crunches, } \\
\text { bridges, planks, extensions }\end{array}$} & EMG & 10 Subjects \\
\hline $\begin{array}{l}\text { Filipa A, Byrnes R, } \\
\text { Paterno M, Myer } \\
\text { G, Hewett T }\end{array}$ & $\begin{array}{l}\text { Neuromuscular } \\
\text { training and core } \\
\text { stability }\end{array}$ & \multicolumn{2}{|l|}{ SEBT ( $Y$ test) } & $\begin{array}{l}\text { SEBT (tape on } \\
\text { floor) }\end{array}$ & $\begin{array}{l}20 \text { female soccer } \\
\text { players }\end{array}$ \\
\hline $\begin{array}{l}\text { Chaudhari A, } \\
\text { McKenzie C, } \\
\text { Borchers J, Best T }{ }^{62}\end{array}$ & $\begin{array}{l}\text { Lumbopelvic } \\
\text { control }\end{array}$ & \multicolumn{2}{|c|}{ Level belt and pitching statistics } & Level belt & $\begin{array}{l}75 \text { male } \\
\text { professional } \\
\text { minor league } \\
\text { baseball pitchers }\end{array}$ \\
\hline Author & What measured & How measured & \multicolumn{2}{|c|}{ Instruments } & Sports used \\
\hline $\begin{array}{l}\text { Peate W, Bates G, } \\
\text { Lunda K, Francis S, } \\
\text { Bellamy K }\end{array}$ & $\begin{array}{l}\text { Strength in trunk } \\
\text { stabilizers and } \\
\text { flexibility }\end{array}$ & FMS & \multicolumn{2}{|l|}{ FMS } & 433 Firefighters \\
\hline $\begin{array}{l}\text { Danis C, Krebs D, } \\
\text { Gill-Body K, } \\
\text { Sahrmann } \mathrm{S}^{7}\end{array}$ & $\begin{array}{l}\text { Whole body } \\
\text { posture, COG } \\
\text { (center of gravity) } \\
\text { Stability }\end{array}$ & $\begin{array}{l}\text { Eyes opened and } \\
\text { closed with feet } \\
\text { apart }\end{array}$ & \multicolumn{2}{|c|}{$\begin{array}{l}\text { Optoelectronic full } \\
\text { body system } \\
\text { measured } \\
\text { kinematics, Force } \\
\text { plates }\end{array}$} & $\begin{array}{l}27 \text { Subjects with } \\
\text { vestibular } \\
\text { hypofunction and } 26 \\
\text { without }\end{array}$ \\
\hline $\begin{array}{l}\text { Bressel E, Yonker J, } \\
\text { Kras J, Heath E }\end{array}$ & $\begin{array}{l}\text { Static and Dynamic } \\
\text { balance }\end{array}$ & $\begin{array}{l}\text { BESS, Star excursion } \\
\text { balance test }\end{array}$ & \multicolumn{2}{|c|}{ Balance pad } & $\begin{array}{l}\text { Basketball, } \\
\text { gymnastics, soccer }\end{array}$ \\
\hline $\begin{array}{l}\text { Moseley G, Hodges } \\
P^{66}\end{array}$ & $\begin{array}{l}\text { Postural motor } \\
\text { learning and control }\end{array}$ & $\begin{array}{l}\text { Arm movements in } \\
\text { pelvic neutral }\end{array}$ & \multicolumn{2}{|l|}{ EMG } & 16 subjects \\
\hline Gribble P, Hertek J ${ }^{63}$ & $\begin{array}{l}\text { Dynamic postural } \\
\text { control }\end{array}$ & $\begin{array}{l}\text { Star excursion } \\
\text { balance test, hip } \\
\text { internal/ external } \\
\text { ROM, and ankle } \\
\text { dorsiflexion }\end{array}$ & \multicolumn{2}{|c|}{ SEBT (tape on floor) } & 30 subjects \\
\hline
\end{tabular}




\section{Core in Relation to Baseball}

When relating the functional movements of baseball athletes back to the anatomy and physiology of the core there seems to be a strong relationship. Kibler et al. ${ }^{5}$ noted that $50 \%$ of the throwing motions force and energy comes from the hip and trunk area. McGill ${ }^{55}$ also believes that throwing athletes can benefit from core stability for the importance of the force production to the upper and lower extremities. ${ }^{38}$ Also, due to the anatomy of the thoracolumbar fascia the core is then linked to the integrated kinetic activities such as throwing. ${ }^{5}$ Rotational core exercises must be incorporated because the abdominals should be strengthened in several planes for strength in multiple directions. ${ }^{9}$ Hirashima et al $(2002){ }^{60}$ demonstrated that with throwing there is a specific muscle pattern that is activated. It begins with the contralateral external oblique and proceeds to the arm. ${ }^{60}$ This idea is directly related to the serape effect. The idea was described about 50 years ago in Logan and McKinneys ${ }^{8}$ book "Kinesiology". This idea is to reinforce that the muscles of the core act as a connector. There is a diagonal pattern that allows the core to take full advantage of the rotational patterns of the cores function. ${ }^{14}$ The serape muscles are rhomboids, serratus anterior, external oblique's, and internal oblique's. This diagonal pattern is also a key concept with baseball athletes whether they are throwing, pitching or hitting. The muscles of the serape effect have a direct relationship to the core; some of them are identified as local and global muscles. Ballistic motions like throwing are considered to be generated by the serape effect. The transferring of forces from a larger body part to a smaller, much like is done during throwing, is also controlled by the serape effect. This concludes that there is a definite relationship of the hip to shoulder in overhead sports. ${ }^{14}$ The general pattern of muscle activation is demonstrated in many athletic tasks, but specifically a baseball throw. ${ }^{5}$ The force is developed from the ground and hips, transferred thru the stiffened core to the distal segments such as the arm and into the baseball. ${ }^{5,55}$ Many sports, including baseball supply the body with muscles imbalances, such as tight hip flexors, rounded forward shoulders; these imbalances are 
also seen in the trunk muscles due to abnormal spinal loading that leads to low back pain. ${ }^{40}$ Spinal stabilization still needs to be task specific as training, and core stability should incorporate a variety of exercises that require different muscles activation patterns. ${ }^{42}$ In baseball it has been thought to test the core in a functional state. One-leg standing balance ability, a one-leg squat and a standing three plane core strength test have been considered to test the functional aspects of core stability. ${ }^{5}$ It is important to include multidirectional strengthening of the hip and trunk muscles to provide dynamic stability. ${ }^{43}$ However, with all of this positive, correlating evidence there are still questions about what specific exercises should be used for not only training but testing the core in healthy athletes. ${ }^{38}$ When searching for these exercises unstable equipment was used to train the core to have better stability. These exercises have been shown to increase the sensitivity of muscles spindles placing the athlete at a higher state of readiness to respond to perturbations to the body. ${ }^{38}$

When monitoring a pitching motion the motion is clearly a total body activity. In the past coaches and athletes have focused on the shoulder and elbow motions to increase efficiency of a pitch. ${ }^{26}$ However, when examining the stages of pitching it is clear that the hips and torso also play a considerable role in the pitching motion and increasing the efficiency. ${ }^{26}$ Previous studies have shown the larger ground reaction force is apparent with pitchers that throw the fastest. ${ }^{26}$ This suggests that the transfer of forces and energy generation from the legs is imperative to a successful pitch. ${ }^{26}$ The idea is clear that a pitcher with poor lumbo-pelvic control will not have a powerful, high velocity, and an accurate pitch compared with a pitcher that has the proper lumbo-pelvic control. ${ }^{26}$ Core stability is not only important in pitchers on the baseball team but also in and out fielders along with anyone that hits. Similar mechanics are found with in and out fielders when compared to pitchers, the only difference may be that in and out fielders have more of a chance to be off balance or have to adjust their throw because of a reaction. This adjustment and change due to a reaction is key to have the core stabilize prior to these movements being damaged. 


\section{Summary}

Core has been defined, the anatomy and biomechanics of the core, the relationship to baseball and the measurements of the core that are used most often in studies was focused on during this literature review. Core has many different definitions and functional uses. This allows core to be controversial in the fundamental functions of it, whether it is considered as a whole or individually. There are multiple ways to measure core when looking at research or anecdotal evidence. However, validity is hard to determine because there is a lack of a gold standard for measurement. Most often measures used lack high-quality evidence of relationships with performance, but there has been evidence of a relationship with core and injury, especially low back pain. 
APPENDIX C

ADDITIONAL METHODS

Table C1. Consent and Information Form

\section{CONSENT AND INFORMATION FORM}

Principal Investigator Michelle Sandrey

Department College of Physical Activity and Sport Sciences

Protocol Number 1312148460

Study Title Test Re-test reliability for Sahrmann lower abdominal core stability test

Co-Investigator(s) Kelsey Dekart

\section{Contact Persons}

If you have any questions, concerns, or complaints about this research, you may contact PI Michelle A. Sandrey, PhD, ATC, at (304) 293 - 0870 or at msandrey@mail.wvu.edu or Co Kelsey Dekart, ATC at 612483-7408 or at kqdekart@mix.wvu.edu

For information regarding rights as a research subject, you may contact the Office of Research Compliance at (304) $293-7073$.

\section{Introduction}

You have been invited to participate in this research study, which has been explained to you by Kelsey Dekart, ATC. This study is being conducted by the Principle Investigator, Michelle A. Sandrey, PhD, ATC and Co-investigator, Kelsey Dekart, ATC in the College of Physical Activity and Sport Sciences at West Virginia University. This research is being conducted to fulfill the requirements for a Thesis in Athletic Training in the College of Physical Activity and Sport Sciences at West Virginia University under the supervision of Michelle A. Sandrey, PhD, ATC.

\section{Purpose(s) of the Study}

The purpose of this study is to determine the test-retest reliability of the Sahrmann core stability test in division II baseball athletes.

\section{Description of Procedures}

You will be asked to fill out a questionnaire to gather demographic information (age, gender, past medical history) as well as to determine eligibility to participate in this study. This will take approximately five to ten minutes to complete. You do not have to answer all of the questions. You will have the opportunity to see the questionnaire before signing this consent form. All completed forms will be kept confidential. If you are an eligible subject, you will be asked to participate in three sessions of measurement. The first will be a training session to allow you to become familiar with the testing measure. The second will be a maximal test. The last testing session will be identical to the second session. Each testing session will take approximately 15 to 20 minutes to complete. Testing will occur on the date and time given to you by the principle investigator. 


\section{Sahrmann lower abdominal test}

The Sahrmann lower abdominal test is a progressive test to measure the stability in your core. There are 5 levels that increase in difficulty. For this test you will have a demonstration period and a training session. The test will be measured by $60 \mathrm{mmHG}$. If you complete each level you will be allowed to move on to the next until unable to complete the test.

\section{Discomforts}

There are no known risks involved in participation in this research study. If at any point during the testing procedures you begin to feel any pain or discomfort, please indicate this to the present investigator. If this occurs the measurement will be suspended immediately and may be rescheduled to a later date once the pain has resolved.

\section{Alternatives \\ You do not need to participate in this study. You may withdraw at any time with no penalty. \\ Benefits \\ You may not receive any direct benefit from this study. However this study procedures and results may help aid in other research. It could help determine a testing measure for athletic trainers to determine core stability in an athletic population. The information gained through this study may eventually benefit others.}

If you are a student and do not wish to participate in this study, your grades nor your position on the team will be impacted. No extra credit is given for participation.

\section{Financial Considerations}

There will be no payments made for participation in this study. There is no cost to participants in this study.

\section{Confidentiality}

Any information about you that is obtained as a result of your participation in this research will be kept as confidential as legally possible. Your research records and test results, just like hospital records, may be subpoenaed by court order or may be inspected by the study sponsor or federal regulatory authorities without your additional consent. In any publications that result from this research, neither your name nor any information from which you might be identified will be published without your consent.

\section{HIPAA}

We know that information about you and your health is private. We are dedicated to protecting the privacy of that information. Because of this promise, we must get your written authorization (permission) before we may use or disclose your protected health information or share it with others for research purposes. This form gives that permission. It also helps us make sure that you are correctly told how this information will be used or disclosed. Please read the information below carefully before signing this form. Please ask any questions you may have about this form or its uses. You can decide to 
sign or not to sign this authorization form. However, if you choose not to sign this authorization form, you will not be able to take part in the research study.

USE AND DISCLOSURE COVERED BY THIS AUTHORIZATION. DO NOT SIGN A BLANK FORM. You or your authorized representative should thoroughly read the information below before signing this form. This form will authorize the following person(s), class(es) of persons, and/or organization(s) to disclose, use, and receive the information: WVU, Michelle A. Sandrey, PhD, ATC, and Kelsey Dekart, ATC. The research site(s) carrying out this study includes WVU. If, during the course of the research, the institution listed above merges with, or is purchased by, another company or institution, this authorization to use or disclose protected health information in the research will extend to the successor, company or institution. A self-reported demographic history that includes information on height, weight, and past medical history of any lower extremity injury is included in this study. After all data has been analyzed the co-investigator will meet with the participants to discuss conclusions made on the reliability of the core stability measures.

SPECIFIC UNDERSTANDINGS. By signing this research authorization form, you give permission for the use and/or disclosure of your protected health information described above. The purpose for the uses and disclosures you are authorizing us to carry out the research study explained to you during the informed consent process. It is also to ensure that the information relating to the research is available to all parties who may need it for research purposes. Your protected health information may be used as necessary for your research related treatment. This information may be redisclosed or used for other purposes if a recipient described in this form is not required by law to protect the privacy of the information. You have a right to refuse to sign this authorization. Your health care outside the study, the payment for your health care, and your health care benefits will NOT be affected if you do not sign this form. However you will NOT be able to take part in the research study described in this authorization if you do not sign this form. If you sign this authorization, you will have the right to cancel it at any time, except to the extent that WVU has already taken action based upon your authorization or needs the information to complete analysis and reports of data for this research study. This authorization will expire six months from today unless you cancel this sooner. To cancel this authorization, please write to the Principal Investigator, Michelle A. Sandrey, PhD, ATC, at: West Virginia University, PO Box 6116, Morgantown, WV 26506. If you cancel this authorization, any information that was collected already for this study cannot be withdrawn. You will NOT be allowed to see or copy the information described on this form as long as the research is in progress, but you have a right to see and copy the information upon completion of the research in accordance with hospital policies. You have a right to receive a copy of this form after you have signed it.

In any publications that result from this research, neither your name nor any information from which you might be identified will be published without your consent.

\section{You May Cancel this Authorization at Any Time by Writing to the Principal Investigator}

Michelle Sandrey, PhD, ATC, at (304) 293 - 0870 or at msandrey@mail.wvu.edu or Co Kelsey Dekart, ATC at 612-483-7408 or at kqdekart@mix.wvu.edu

If you cancel this authorization, any information that was collected already for this study cannot be withdrawn. Once information is disclosed, according to this authorization, the recipient may redisclose it and then the information may no longer be protected by federal regulations. 
You have a right to see and make copies of your medical records. You will not be able to see or copy your records related to the study until the sponsor has completed all work related to the study. At that time you may ask to see the study doctor's files related to your participation in the study and have the study doctor correct any information about you that is wrong.

This authorization will expire at the end of the study unless you cancel it before that time (or has a specific expiration date).

\section{Voluntary Participation}

Participation in this study is voluntary. You may refuse to participate in this study. You may withdraw from this study at any time. Refusal to participate or withdrawal will not affect your future care, or your class standing or grades, as appropriate and will involve no penalty to you or your position on the team. In the event new information becomes available that may affect your willingness to allow you to participate in this study, this information will be given to you so that you can make an informed decision about whether or not to continue your participation. You have been given the opportunity to ask questions about the research, and have received answers concerning areas you did not understand.

Upon signing this form, you will receive a copy.

I willingly consent to participate in this research.

Signature of Subject Printed Name Date Time

The subject has had the opportunity to have questions addressed. The subject willingly agrees to be in the study.

Signature of Investigator Printed Name Date Time

Upon signing this form, you will receive a copy. I willingly consent to participate in this research

Signature of Subject Printed Name Date Time

The subject has had the opportunity to have questions addressed. The subject willingly agrees to be in the study. 
Age:

Position:

Year in School: (Circle one) Freshmen / Sophomore / Junior / Senior / Graduate Student Year on the Field:

Height:

Weight:

1. Have you had a history of upper body injury in the past six months that has required medical intervention? If so, what was the diagnosis?

2. Have you had a history of lower body injuries within the past six months that has required medical intervention? If so, what was the diagnosis?

3. Are you currently taking any medications that may affect your balance or coordination?

4. Are you currently doing any core stability training? If yes please explain what core stability training you are currently involved in. 
Table C3. Data Collection Sheet

Subjects Number:

Age:

Position:

Height:

Weight:

Data collection sheet for Sahrmann Core Stability Test

Week: 2 / 3

Level 1: Pass / Fail Comments:

Level 2: Pass / Fail Comments:

Level 3: Pass / Fail Comments:

Level 4: Pass / Fail Comments:

Level 5: Pass / Fail Comments: 
1. All positions started supine in the hook lying position, with the spine in a neutral or comfortable position.

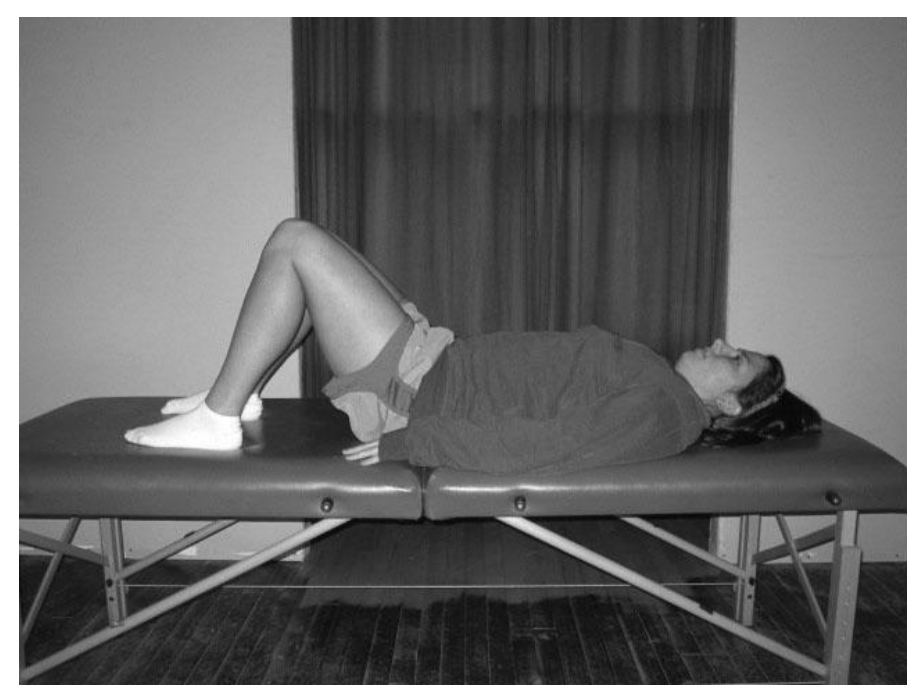

2. Level 1: The first movement was with one leg moving into $90^{\circ}$ hip flexion. Maintaining abdominal control, the opposite leg then matched the first by moving into $90^{\circ}$ of hip flexion.

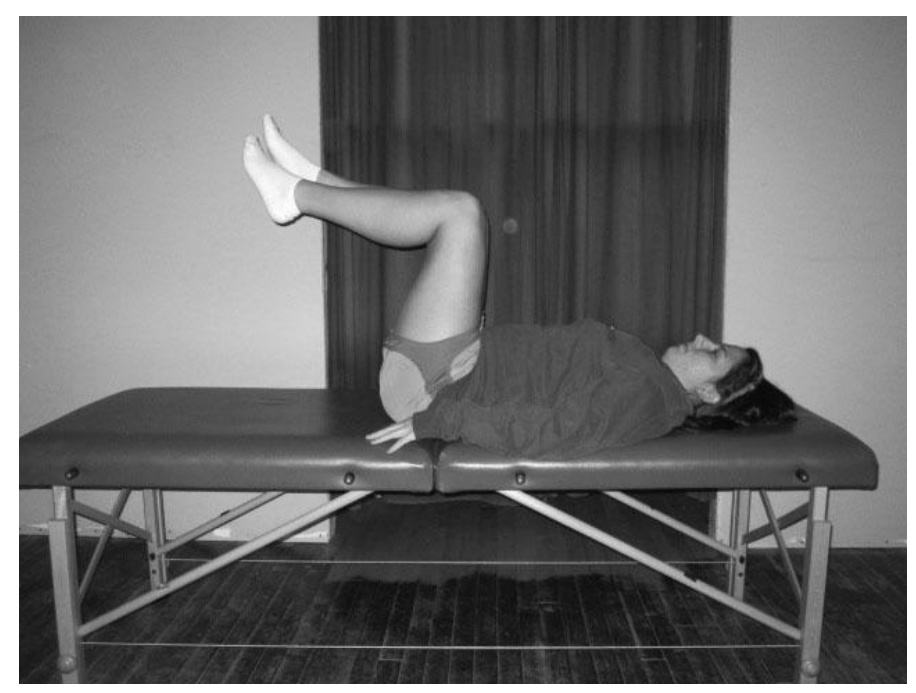

3. One leg at a time was lowered to the table again, maintaining abdominal control by staying in spine neutral. 


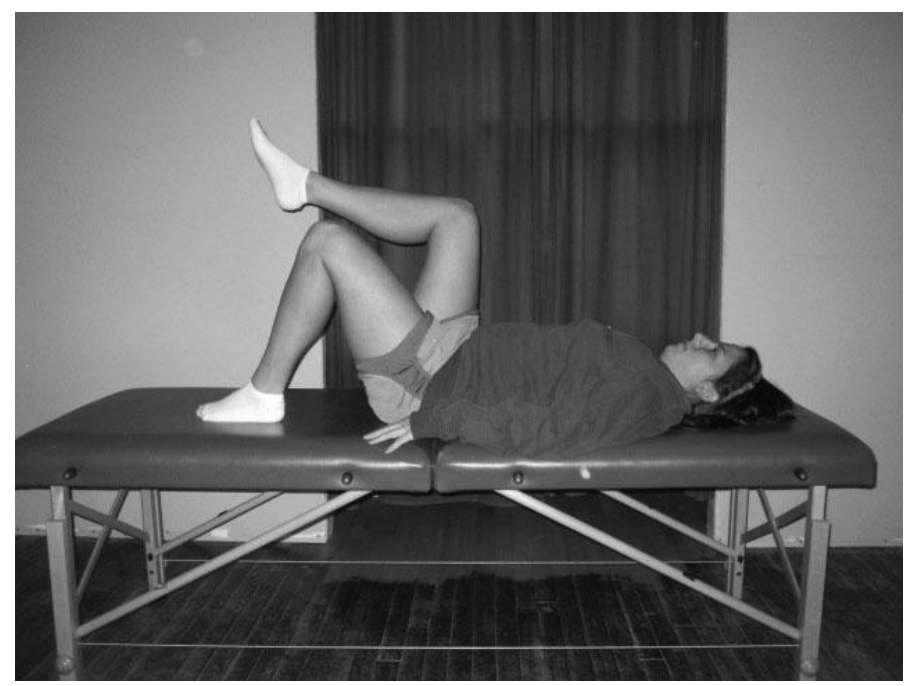

Figure C2. Sahrmann Lower Abdominal Level 2

1. Level 2 begins again at the same position, hook lying and was raised one leg into $90^{\circ}$ hip flexion, and matches position with the opposite leg.

2. One leg was lowered to a heel touch position on the table and extended out along the table then returned to the starting position.

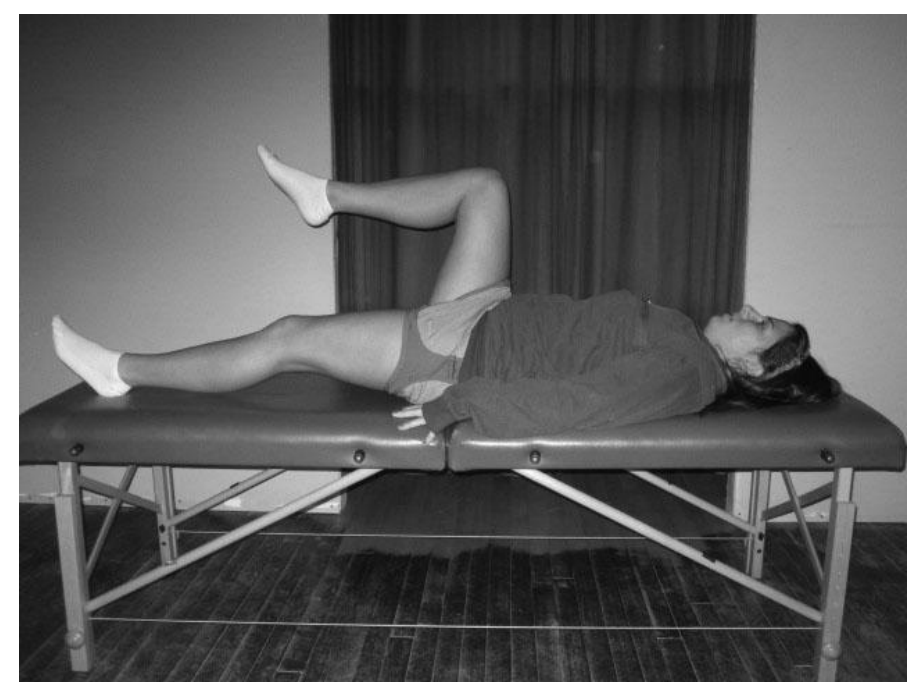

3. This was also done with the opposite leg. 


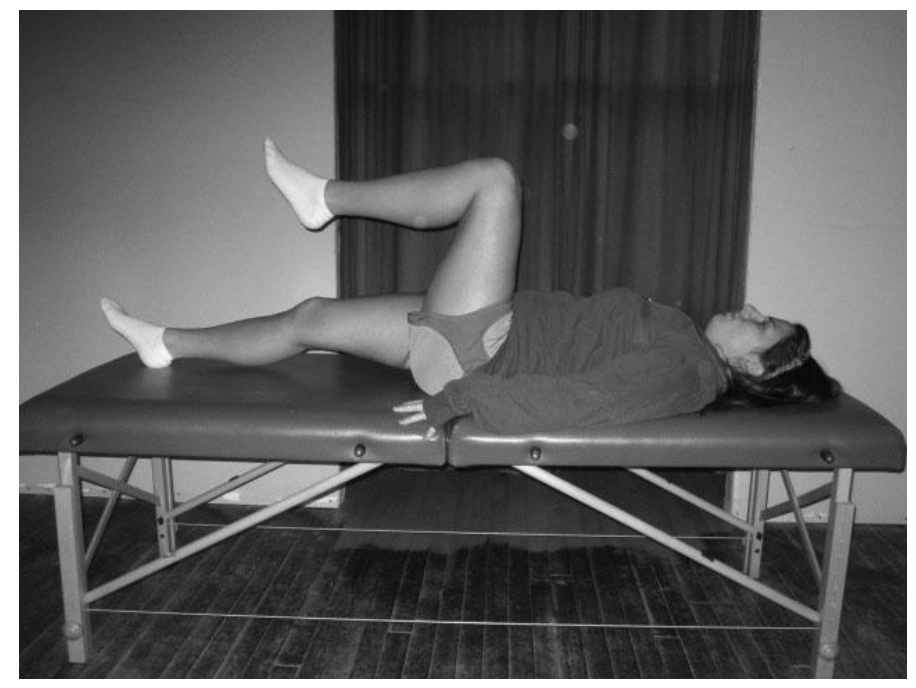

Figure C3. Sahrmann Lower Abdominal Level 3

1. Level 3 started with both legs being brought up into $90^{\circ}$ hip flexion.

2. One leg at a time is extended out this time not contacting the table but remaining 1-2 inches above the table.

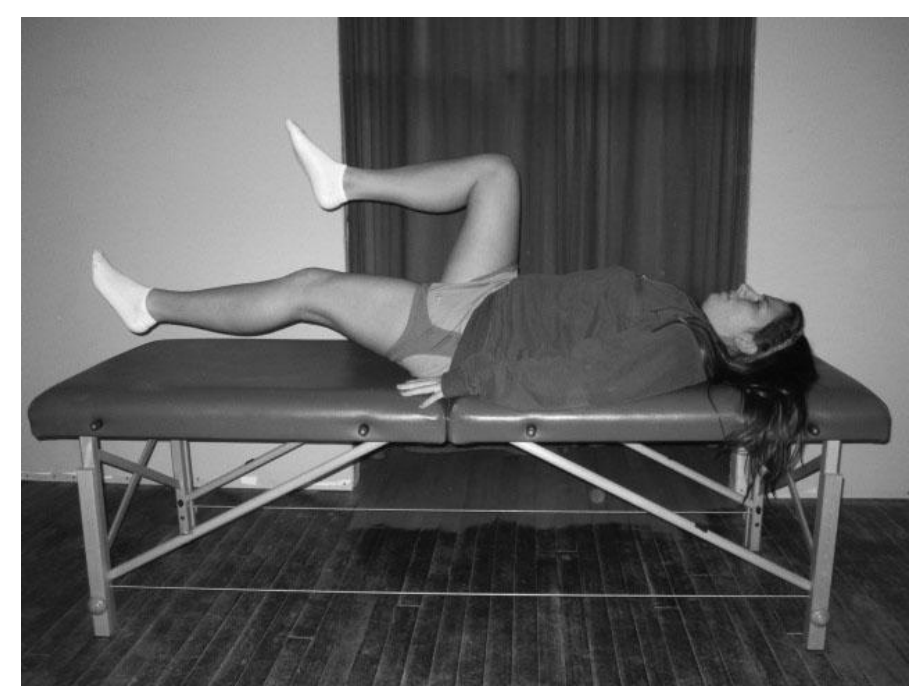

3. The opposite leg mimiced the first and the patient returned back to the hook lying position on the table. 
1. Level 4 started with athlete fully extended lying on the table. Heels will be in contact with the table.

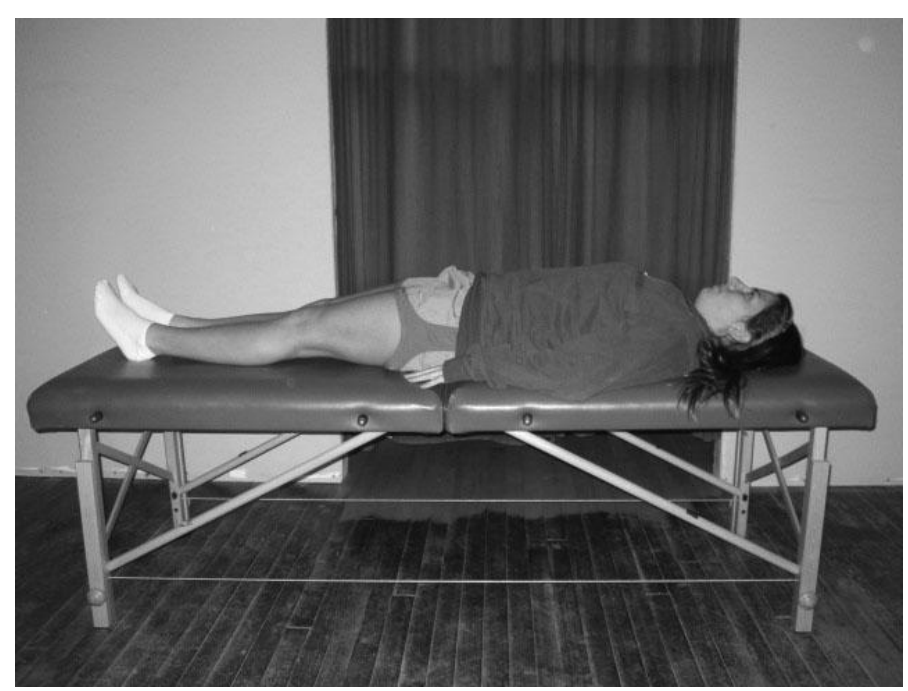

2. The knees were flexed to a fully flexed position and extended back down to the table. This was done while maintaining spine neutral.

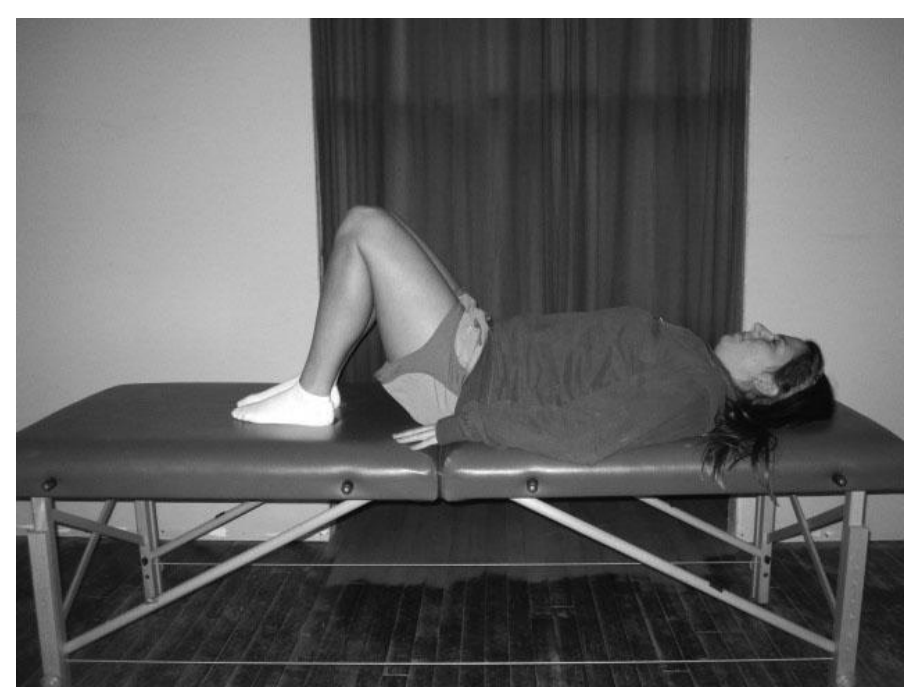


1. Level 5 began again with legs extended lying on the table.

2. Both legs were lifted off the table then the knees were flexed and brought up into hip flexion.
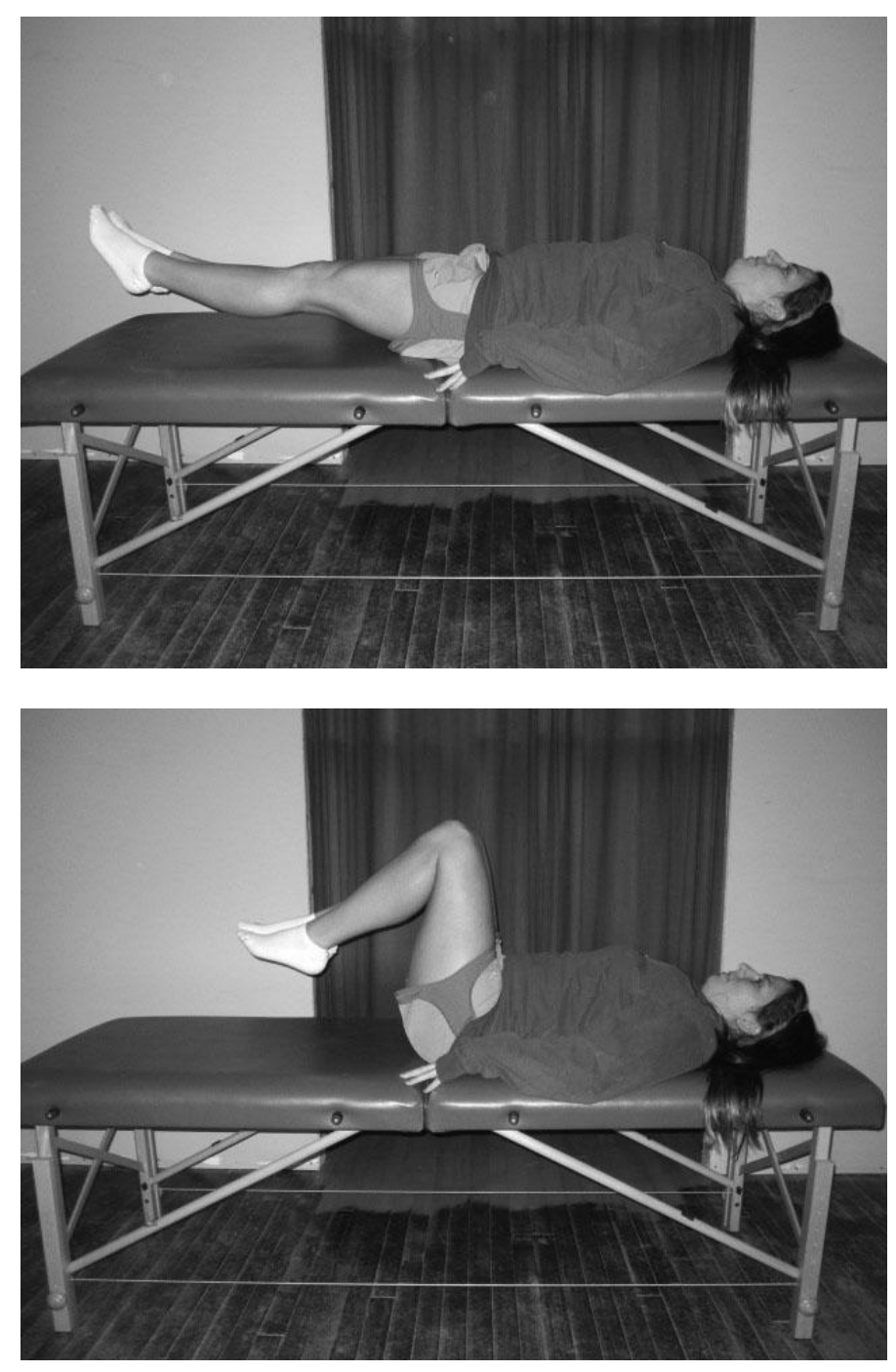

3. Patient then extended the knees out and lower both legs down towards the table. All levels must be completed maintaining lumbar stabilization and spine neutral. 


\section{APPENDIX D}

ADDITIONAL RESULTS

Table D1. ICC Scores, Standard Error of the Measurement and Means and Standard Deviation Between Weeks

\begin{tabular}{lllll} 
& Week 2 & Week 3 & ICC $_{3,1}$ & SEM \\
Sahrmann & $0.867 \pm 0.899$ & $1.033 \pm 0.809$ & 0.649 & 0.302 \\
\hline
\end{tabular}

Key: $\mathrm{ICC}_{3,1}=$ Intraclass Correlation Coefficient, ; SEM $=$ Standard Error of the Measurement 


\section{APPENDIXE \\ RECOMMENDATIONS FOR FUTURE RESEARCH}

1. Maintain same surface for all participants.

2. Test prior to athletic season, without other training to create any feeling of fatigue.

3. Have a script for testing purposes, to maintain identical testing directions.

4. Measure validity of the Sahrmann test.

5. Matching protocol with other athletic groups.

6. Determining male and female differences.

7. Strive to find a relationship between injury and weakened core. 


\section{ADDITIONAL REFERENCES}

42. Behm D, Drinkwater E, Willardson J, Cowley $\mathrm{P}$. The role of instability rehabilitative resistance training for the core musculature. Strength Cond. 2011:33(3); 72-81.

43. Samson K, Sandrey M, Hetrick A. A core stabilization program for tennis athletes. Athl Ther. 2007:12(3); 41-46.

44. Sharma A, Geovinson S, Sandhu S. Effects of a nine-week core strengthening exercise program on vertical jump performances and static balance in volleyball players with trunk instability. $J$ Sports Med Phys Fitness. 2012:52; 606-615.

45. Akuthota V, Nadler S. Core strengthening. Arch Phys Med Rehabil. 2004:85(1); S86-S92.

46. Boyle M. Core training and glute activation. PT on the net. 2005. Accessed September 16, 2013.

47. Nelson N. Diaphragmatic breathing: The foundation of core stability. Strength Cond. 2012:34(5); 34-40.

48. Cissik J. The role of core training in athletic performance, injury prevention, and injury treatment. Strength Cond. 2011:33(1); 10-15.

49. Richardson C, Snijders C, Hides J, Damen L, Pas M, Storm J. The relation between the transverses abdominis muscles, sacroiliac joint mechanics, and low back pain. SPINE. 2002:27(4); 399-405.

50. Omkar S, Vishwas S. Yoga techniques as a means of core stability training. Bodywork Movement Thera. 2007:13; 98-103.

51. Starkey C, \& Ryan J. (2009). Evaluation of Orthopedic and Athletic Injuries. $3^{\text {nd }}$ Edition. F.A. Davis.

52. Moore KL, Dalley AF. Clinically Oriented Anatomy. $6^{\text {th }}$ ed. Baltimore, MD: Lippincott Williams \& Wilkins; 2010 (M \& D)

53. Vasseljen O, Unsgaard-Tondel M, Westad C, Mork P. Effect of core stability exercise on feedforward activation of deep abdominal muscles in chronic low back pain. SPINE. 2012:37(13); 1101-1108.

54. Yu J, Lee G. Effect of core stability training using pilates on lower exeremity muscles strength and postural stability in healthy subjects. Isokinetic and Exercise Science. 2012:20; 141-146. 
55. McGill S. Core training:Evidence translating to better performance and injury prevention. Strength Cond.. 2010:32(3); 33-46.

56. Arokoski J, Valta T, Airaksinen O, Kankaanpaa M. Back and abdominal muscle function during stabilization exercises. Arch Ohys Med Rehabil. 2001:82; 1089-1098.

57. Sole G, Milosavljevic S, Sullivan S, Nicholson H. Running-related hamstring injuries: A neuromuscular approach. Phys Thera. 2008:13(2); 102-110.

58. Pel J, Spoor C, Pool-Goudzwaard A, Hoek van Dijke G, Snijders C. Biomechanical amalysis of reducing sacroiliac joint sear load by optimization of pelvic muscle and ligament forces. Annals of Biomedical Engineering. 2008:36(3); 415-424.

59. O'Sullivan P. Lumbar segment 'instability': Clinical presentation and specific stabilizing exercise management. Manual Therapy. 2000:5(1); 2-12.

60. Hirashima, M., Kadota, H., Sakurai, S., Kudo, K., \& Ohtsuki, T. Sequential muscle activity and its functional role in the upper extremity and trunk during overarm throwing. Sports Sciences. 2002: 20(4); 301-310.

61. Lariviere C, Gagnon D, De Oliveria E, Henry S, Mecheri H, Dumas J. Reliability of ultrasound measures of the transverses abdominis: Effect of task and transducer position. American Academy of Physcial Medicine and Rehabilitation. 2013:5; 104-113.

62. Filipa A, Byrnes R, Paterno M, Myer G, Hewett T. Neuromuscular training improves performance on the star excursion balance test in young female athltetes. J Orthop Sports Phys Ther. 2010: 40(9); 551-558.

63. Gribble $\mathrm{P}$, Hertel J. Consideration for normalizing measures of the start excursion balance test. Measurement in Physical Education and Exercise Science. 2003:7(2); 89-100.

64. Tse M, McManus A, Masters R. Development and validation of core endurance intervention program: Implications for performance in college-aged rowers. Strength Cond. 2005:19(3); 547552.

65. Konrad P, Schmitz K, Denner A. Neuromuscular Evaluation of trunk-training. Ath/ Train 2001:36(2); 109-118.

66. Bressel E, Yonkers J, Kras J, Heath E. Comparison of static and dynamic balance in female collegiate soccer, basketball, and gymnastics athletes. Athl Train. 2007:42(1); 42-46. 